\title{
In Vivo Microscopy in Neurosurgical Oncology
}

Hany Osman, $\mathrm{MD}^{1}$, Joseph Georges, DO, $\mathrm{PhD}^{2}$, Deena Elsahy, $\mathrm{BS}^{3}$, Eyas Hattab, $\mathrm{MD}^{4}$, Steven Yocom, $\mathrm{DO}^{2}$, Aaron A. Cohen-Gadol, MD, $\mathrm{MSc}^{5}$

\footnotetext{
${ }^{1}$ Massachusetts General Hospital and Harvard Medical School, Wellman Center for Photomedicine, Boston, Massachusetts

${ }^{2}$ Philadelphia College of Osteopathic Medicine, Department of Neurosurgery, Philadelphia, Pennsylvania

${ }^{3}$ Indiana University School of Medicine, Indianapolis, Indiana

${ }^{4}$ University of Louisville, Department of Pathology and Laboratory Medicine, Louisville, Kentucky

${ }^{5}$ Goodman Campbell Brain and Spine and Indiana University Department of Neurological Surgery, Indianapolis, Indiana
}

\section{E-mail addresses}

Hany Osman: haosman@mgh.harvard.edu

Joseph Georges: joseph.georges@asu.edu

Steven Yocom: Yocom-Steven@cooperhealth.edu

Deena Elsahy: daelsahy@iupui.edu

Eyas Hattab: eyas.hattab@louisville.edu

Aaron A. Cohen-Gadol: acohenmd@gmail.com

Key words: In-vivo; microscopy; neurosurgery; glioma; oncology

\section{Correspondence:}

Aaron A. Cohen-Gadol, MD, MSc

Goodman Campbell Brain and Spine

Indiana University Department of Neurological Surgery

355 W. 16th Street, Suite \#5100

Indianapolis, IN 46202

Phone: $317-362-8760$

Fax: 317-924-8472

E-mail: acohenmd@gmail.com

Abbreviations used: 2-HG: 2-hydroxyglutarate; 5ALA: 5-aminolevulinic acid; BLZ-100: tumor paint; CARS: coherent anti-stokes Raman scattering; CRM: confocal reflectance microscopy; CRS: coherent Raman spectroscopy; LSCE: laser scanning confocal endomicroscopy; FNa: fluorescein sodium; FLIM: fluorescence lifetime microscopy; ICG: indocyanine green; OCT: optical coherence tomography; SRS: stimulated Raman scattering

This is the author's manuscript of the article published in final edited form as: 


\begin{abstract}
Intraoperative neurosurgical histopathologic diagnoses rely on evaluation of rapid tissue preparations such as frozen sections and smears with conventional light microscopy. Though useful, these techniques are time consuming and therefore unable to provide real-time intraoperative feedback. In vivo molecular imaging techniques are emerging as novel methods for generating real-time diagnostic histopathologic images of tumors and their surrounding tissues. These imaging techniques rely on contrast generated by exogenous fluorescent dyes, autofluorescence of endogenous molecules, fluorescence decay of excited molecules, or light scattering. Large molecular imaging instruments are being miniaturized for clinical in vivo use. This review discusses pertinent imaging systems that have been developed for neurosurgical use and imaging techniques currently under NADPH development for neurosurgical molecular imaging.
\end{abstract}

\title{
INTRODUCTION
}

Enhancing the gross extent of resection for gliomas improves patient survival. ${ }^{1,2}$ Extensive gross resection of low-grade and high-grade lesions not only significantly improves survival, but also increases time to recurrence. ${ }^{3}$ The addition of gross fluorescent contrast agents, such as 5-ALA for the identification and resection of gliomas, provides further improvement in progression-free survival for glioma patients. ${ }^{4}$ This improvement is attributed to the increased rate of gross total resection, approximately double, with the addition of intraoperative tumor fluorescence contrast. ${ }^{4}$

Increasing extent of resection must also aim to preserve eloquent brain as new postoperative neurological deficits are correlated with increased patient morbidity and decreased survival rates. ${ }^{5-7}$ With detailed preoperative planning, postoperative neurological morbidity may be insignificant with respect to the extent of surgery. ${ }^{4,7,8}$ The general consensus leads us to believe that better techniques are required for improved surgical localization and removal of neoplastic tissue, and avoidance of healthy tissue to maximize the benefit of cytoreduction and risk reduction. $^{9}$

Intraoperative microscopic evaluation of tissues is currently possible via frozen sections and tissue smears. Though useful, these techniques require anywhere from several minutes to occasionally an hour or more for feedback and can damage tissue, creating imaging artifacts, ${ }^{10-13}$ Also, given the nature of neurological tissue and neurosurgery, it is challenging to view threedimensionally orient tissue biopsies in a practical manner for localization and complete removal of tumor-positive areas. For this purpose, frozen sections and smears are typically used for their diagnostic confirmatory purpose rather than guidance for extent of resection.

This article reviews pertinent current peer-reviewed manuscripts assessing in vivo and molecular imaging techniques with potential neurosurgical applications. We expand on the hypotheses, 
benefits, and limitations of the current technologies for their application in neurosurgery. This review does not address functional brain imaging studies or studies examining basic tumor microenvironment and focuses on surgical oncology applications. The studies examining application of imaging technology by studying applicability in freshly resected and ex-vivo specimens from brain tissues were also included.

\section{Laser Scanning Confocal Endomicroscopy}

Laser scanning confocal endomicroscopy (LSCE) is a noninvasive imaging technique permitting in vivo histologic imaging with miniaturized endoscopic probes at cellular resolution. Cellular detail may be visualized by application of exogenous fluorescent contrast agents or by label-free imaging approaches that generate contrast based on endogenous fluorophores or tissue photon-scattering properties. ${ }^{14-16}$ Currently, most diagnostic LSCE is conducted with use of exogenous contrast agents. Emerging label-free approaches include tissue visualization via autofluorescence, in which endogenous fluorophores are excited to generate fluorescence contrast and reflectance mode confocal microscopy which visualizes tissues based on the variable refractory differences of microscopic structures. ${ }^{17}$

One advantage confocal microscopy provides over conventional microscopy is its ability to optically section through thick tissues. To allow for optimum tissue contact, the microscope can be introduced to the tissues endoscopically or topically via a miniaturized optical apparatus. Alternatively, excitation light and images can be transmitted to and from the tissues to the microscope via a flexible imaging fiber-optic conduit. The clinical utility of confocal endomicroscopy for histologic evaluation is well established for evaluation of the gastrointestinal $\operatorname{tract}^{18,19}$ and is being extensively investigated for utility in multiple other organ systems, including the brain.

Differences in morphologic appearance of tissue in ex-vivo specimens with topically applied fluorescent agents and in vivo specimens with injected agents must be noted. Injected sodium fluorescein highlights a fluorescent extracellular background with nuclear cellularity representing dark shadows. Strong fluorescence signal is usually demonstrated in tumor tissue due to increased extravasation of the agent and small hemorrhages. ${ }^{20}$ Also, fluorescent vessels appear bright and are simple to identify. ${ }^{20}$ Another issue with in vivo images obtained with confocal systems is the motion artifact that complicates image interpretation. Motion artifacts during acquisition of images result from movements of the portable probe or of the tissue because of pulsation and other movement. This increases the number of images needed to be captured in vivo compared with ex vivo imaging before diagnosis. ${ }^{21}$ Development of imaging systems with higher frame rates will minimize motion artifacts in future devices.

Although cellular and architectural detail is often sufficient, diagnostic challenges may result from the unconventional plane of sectioning. In most areas of the body, interpretation of 
the images is dependent to some extent on the plane of tissue at imaging. LSCE provides en-face sectioning of the tissue and can be contrary to the conventional plane of sectioning for histology and may make interpretation of small foci of invasion more challenging. ${ }^{22}$

Current FDA-approved diagnostic fluorescence contrast agents for neurosurgery include fluorescein sodium (FNa), indocyanine green (ICG), 5-aminolevulinic acid (5ALA), and tumor paint (BLZ-100). These agents are in various levels of clinical testing and approval and have been thoroughly reviewed in the literature. ${ }^{23}$ Fluorescein sodium and ICG are nonspecific agents that provide cellular contrast between all structures within the field of view. Fluorescein sodium has the advantage of excitation and emission within the visible wavelength, allowing real-time macrofluorescent imaging when viewed through the optics of a surgical microscope. Indocyanine green is an infrared fluorophore that allows imaging of deeper cellular structures; however, ICG requires digital processing for viewing due to emission wavelength beyond what is detected by the human eye. Five-aminolevulinic acid and BLZ-100 are specific fluorophores and selectively label tumor cells within the brain. Their ability to exploit the selective labeling to safely enhance extent of resection is currently in various phases of clinical review. ${ }^{24}$

Outside of neurosurgery, the most common fluorescent contrast agents for clinical applications are acriflavine hydrochloride $0.05 \%$, fluorescein, and indocyanine green (ICG). ${ }^{25-29}$ When fluorescein and topical acriflavine are combined, it is possible to calculate nuclear cytoplasmic ratios, which are useful indicators for cellular differentiation. Simultaneous imaging of multiple fluorophores is now possible with several clinical LSCE systems with multichannel imaging capabilities. ${ }^{30}$

Flexible Probe Confocal Endomicroscopy: Images obtained utilizing a flexible probe attached to a LSCE have an overall good quality and are comparable to conventional histologic images. ${ }^{31}$ The flexible imaging fiber optic extends the imaging field by transmitting the image through a bundle of optical fibers (Fig. 1a). Each fiber acts to transmit light corresponding to the light intensity of the area imaged. When multiple fibers are bundled together, each fiber acts as a pixel; therefore the resolution of the imaging system depends on the number and size of fibers within a bundle. ${ }^{32}$ The space between the individual optical fibers superimposes a honeycomb pattern over the image. Although the resolution and quality of images is reduced because of the honeycomb artifact, the fiber optic is very small and flexible compared with miniaturized or rigid microscopes. This allows for intraoperative freedom when imaging. ${ }^{32}$

Charalampaki et al. studied the neurosurgical utility of confocal laser endomicroscopy in 150 patients and ex vivo specimens. Tumors examined using the microscope ranged from benign and malignant primary brain tumors, to metastases. In general, both benign and malignant tumors in the brain exhibited increased cellularity and vascularity. Vascular proliferation appears as dark spots with topical application of most fluorescent agents and appears bright with intravascular injection of fluorescent agents in vivo. ${ }^{31,33}$ The use of fluorescein as an injectable agent for in vivo diagnoses demonstrated the ability to differentiate normal from abnormal tissue. ${ }^{33}$ Five- 
aminolevulinic acid injection resulted in images that were harder to interpret. ${ }^{33}$ Large structural formations were generally easy to identify in the tissues. Examples include psammoma bodies, calcifications, Rosenthal fibers, palisading, and pseudorosettes (Fig. 1b).

For the same reason, other studies found that the sensitivity of endomicroscopy in diagnosing meningiomas with identifiable structures such as psammoma bodies to be significantly higher. ${ }^{21}$ However, confocal endomicroscopy was unable to differentiate highgrade from low-grade meningiomas with a satisfactory degree of reproducibility and confidence. ${ }^{31}$ This demonstrates one of the main limitations of in vivo microscopy. It is apparent that it is difficult to interpret cytologic features of pleomorphism, nuclear cytoplasmic ratios, and general atypia. $^{31}$ Also critical histologic features of mitosis, endothelial proliferation, and necrosis are not readily identifiable. ${ }^{33}$ Detection of some of these features is possible using miniaturized confocal endomicroscopy, as discussed later, and this demonstrates the limitation of a fiber optic in producing high-quality images.

Rigid Probe Confocal Endomicroscopy: Imaging devices composed of a confocal microscope with an attached rod lens are available ${ }^{34}$. The rod lens acts as a conduit for the transfer of images from the tissue surface to the microscope objective. Although the glass lens is not flexible, images produced using this method tend to have a better quality and are less pixelated when compared with those of flexible fiber optics. ${ }^{35}$

The EndoMAG1 is a confocal endomicroscope with a rigid probe that was investigated for neuro-oncological applications. This microscopy technique achieves a resolution of $2 \mu \mathrm{m}$ and has a field of view with a diameter of $300 \mu \mathrm{m} .{ }^{34}$ Examination of the specimens using the rigid probe confocal system generated images comparable to other confocal systems ${ }^{34}$ and allowed differentiation between grey and white matter, membranes, and diagnosis of different tumor types.

In certain tumors, the diagnostic information achieved with the microscope were sufficient; for example, meningiomas with prominent psammoma bodies were readily visualized, however, as with other confocal systems, interpretation of other common histologic diagnostic criteria was challenging $^{34}$ (Fig. 2). An interesting advantage of the EndoMAG1 confocal system imaging is that images produced after the addition of a contrast agent (methylene blue) were similar to the results produced by imaging of native brain without the addition of a contrast agent; this finding suggests the ability of this microscope in detecting autofluorescence.

Miniaturized Confocal Microscopy: Miniaturization of the optical components of a confocal microscope converts it into a hand-held rigid probe with a diameter less than $10 \mathrm{~mm}$. This tool provides portability and direct microscopic imaging of tissues when integrated into endoscopic and surgical procedures. ${ }^{31}$ Commercially available miniaturized confocal microscopes such as the Optiscan are currently available for clinical and research utility (Fig 3a). The addition of fluorescent contrast agents such as fluorescein or acriflavine are usually required 
for the production of interpretable images. The images produced using the system are theoretically superior to those obtained using a fiberoptic or rigid rod lens conduit as there is no deterioration in the image quality by the conduit.

In fact, one study demonstrated the ability of this microscopy technique in detecting subnuclear structures such as nucleoli with acriflavine as a contrast agent. ${ }^{20}$ Detection of mitoses in vivo was also possible and was demonstrated within high grade gliomas. ${ }^{20}$ In studies examining the accuracy of the confocal system imaging of ex vivo biopsies obtained from the brain, or animals, strong discerning ability of the microscope was demonstrated with cytological and architectural detail comparable to histology. Detection of the transition zone between neoplastic and healthy tissue was considered easy in grafted gliomas ${ }^{20}$ (Fig. 3b). Additionally, detection of single malignant cells distant from the main tumor was possible. ${ }^{20}$

Meningiomas are generally among the tumors readily identifiable using in vivo microscopy given their architectural cytostructure. In a study examining grafted meningiomas in mice using the miniaturized handheld confocal system, variable histologic variants were demonstrable in vivo, including the ability of this microscope to demonstrate small foci of invasion among aggressive meningiomas. ${ }^{21,22}$ Although this imaging modality is able to identify most other tumors studied, such as meningiomas, schwannomas, epidermoid cysts and craniopharyngiomas, ${ }^{20,31}$ it may require that multiple images be acquired before an image with enough data to make a diagnosis is captured.

The number of in-vivo images captured on average before a diagnostic image is produced is approximately $14 .^{21}$ This requires a mean imaging time of a single field of approximately 5.8 minutes, which is significantly shorter than the time required for frozen section interpretation. ${ }^{36}$ However, large area scanning of the tumor bed may be too time consuming and not practical, and confocal imaging in general may be more useful in imaging suspicious foci within the tumor bed. $^{22}$ In the study by Martirosyan et al., ${ }^{21}$ the sensitivity (91\% for gliomas and $97 \%$ meningiomas) and specificity (91\% for gliomas and $97 \%$ of meningiomas) of in -vivo acquisition were comparable to those of frozen sections. ${ }^{21}$

\section{Advantages of LSCE}

- Generates high quality of images with good nuclear and subnuclear detail, allowing for accurate diagnoses

- High accuracy for identifying various types of tumors

- Can be integrated into hand-held probes or flexible fiber optics for practical application during surgery

- Shows good visibility of vascularity and vascular structures with injected fluorescent agents

- Can be combined with confocal reflectance microscopy for multimodal microscopy 


\section{Disadvantages of LSCE}

- Usually requires the addition of contrast agents

- Difficulty in identifying some histologic features such as mitoses and nuclear pleomorphism

- Associated with significant motion artifact in vivo

\section{Confocal Reflectance Microscopy}

Confocal reflectance microscopy (CRM) is a low-energy optical imaging modality that can rapidly assess tissue samples without physical manipulation or application of exogenous contrast agents. ${ }^{37} \mathrm{CRM}$ generates contrast based on tissue specific backscatter and reflection of photons.. CRM introduces a small fraction of energy into tissue compared with fluorescent imaging techniques since it does not rely on fluorophore excitation.

One of the main advantages of confocal reflectance microscopy is that it generally does not require preparation or staining of the tissues for imaging, although acetic acid has been shown to enhance nuclear contrast. ${ }^{38-42}$ Acetic acid causes compaction of nuclear chromatin making them appear brighter. ${ }^{38}$ In xenograft and clinical biopsies, CRM have shown utility for providing detailed histopathologic images of normal brain and neoplastic brain (Fig. 7a(b)), (Fig. $7 \mathrm{~b}(\mathrm{~b})$ ). Like confocal fluorescence microscopy, confocal reflectance microscopy possesses the ability to change the depth of imaging, creating optical sections within the tissue. However, since the detected signal is a scattered signal, the depth of imaging is limited to tissues with high scattering.

Furthermore, work in ex-vivo and animal models suggests CRM can provide detailed microscopic interrogation without alterations to the molecular integrity of the tissues. ${ }^{43,44}$ Since CRM is a nondestructive technique, It may be useful in determining cellular and viable tissues prior to biobanking. ${ }^{31}$ Further work is required to determine if the ex vivo imaging utility of CRM can be translated for in vivo applications. Fiber optic probe integration with confocal reflectance microscopes allowing for flexible endoscopic imaging has been demonstrated, but not yet customized for neurosurgical applications. ${ }^{45,46}$

\section{Advantages of CRM}

- Generates high-resolution images

- Delivers low energy to tissue

- Can optically section thick tissue

- No exogenous contrast agents required

- Does not disrupt tissue molecular integrity 


\section{Disadvantages of CRM}

- Limited to imaging depth of 150 microns, dependent on tissue-scattering properties

- Requires learning curve for image interpretation

- Technology has not been miniaturized for clinical neurosurgical use

\section{Raman Spectroscopy}

Raman spectroscopy is an analytical method that relies on scattering of light by vibration of molecules within a given specimen. ${ }^{47}$ The vibrating molecules and bonds shift a small fraction of the scattered photons into a new frequency. These shifts correspond to the chemical composition of the molecule. Fatty acids, for example, produce signature spectral shifts, allowing their identification.

Microscopy techniques that rely on Raman scattering may be direct, in which a shift characteristic for a molecule could be used to map its distribution within an area of tissue. Alternatively, thousands of Raman spectra can be recorded from different spots within a microscopic field and an image is generated based on the aggregate compositions within the area. Several imaging techniques based on the Raman concept have evolved and have been studied in several areas of the body, including the brain.

Earlier spectroscopic studies of excised human gliomas and other brain tumors showed that spectroscopy can differentiate grey from white matter ${ }^{48}$ and necrotic (cholesterol rich) from viable tissues. ${ }^{49}$ These distinctions are possible because of significant differences in lipid compositions of these compartments. Unfortunately, the method lacks sufficient sensitivity to differentiate tumor from normal brain tissue. ${ }^{50}$ Gliomas (grades II - IV), studied in early spectroscopy studies, showed spectra identical to gray matter. ${ }^{50}$ Further developments using near infra-red spectroscopy allow discrimination between tumor and normal brain. ${ }^{51,52}$ In addition to its discriminatory advantage, the use of near infra-red Raman spectroscopy of the brain reduces the risk of tissue damage.

Unlike fluorescence microscopy, Raman spectroscopy and microscopy do not require the addition of exogenous contrast agents. Other advantages include the ability to transmit the measurements through a fiber optic hand held probe allowing for intraoperative use. ${ }^{53-56}$ (Fig. 4a). Perhaps the main drawback of the conventional spontaneous Raman scattering in the brain is lack of satisfactory sensitivity to detect minute Raman shifts necessary for tumor diagnosis. This results in decreased discriminatory ability and long acquisition time which may result in tissue damage.

Coherent Raman spectroscopy (CRS) has significantly improved Raman spectroscopy sensitivity. CRS typically uses two pulsed laser sources and drives the Raman signal collected toward an easier-to-detect spectrum (away from interference with emitted fluorescence noise). 
This allows considerable isolation and magnification of the signal, thus increasing sensitivity. The two major methodologies of CRS studied in the brain are coherent anti-stokes Raman scattering (CARS) and stimulated Raman scattering (SRS). Stimulated Raman spectroscopy mapped to graphical representation demonstrated mitotic figures along with detailed cytological and architectural features (Fig. 4b). CRS techniques also improve the quality of the signals collected by measuring the spectra within a thin slice of tissue, as opposed to collecting aggregated spectra from depths of up to $1 \mathrm{~mm} .{ }^{57}$

With a high specificity (91\%) and sensitivity (93\%), Jermyn et al. demonstrated the powerful ability and accuracy of SRS in identifying malignant tissues intraoperatively in human brain. ${ }^{55}$ In addition to the ability of identifying densely malignant and normal tissues, the SRS probe has the ability of detecting normal brain infiltrated with as few as 17 cancer cells per $0.0625 \mathrm{~mm}{ }^{255}$

\section{Advantages of Raman Spectroscopy}

- Can accurately detect brain tumors, including gliomas (grades 2-4)

- Coherent Raman methods provide high sensitivity and resolution for detecting single malignant cells

- No contrast agent is required for brain imaging

- Can be integrated in endoscopic or hand-held probes

\section{Disadvantages of Raman Spectroscopy}

- Limited to imaging depth of 150 microns

- Interference from extraneous operative light may require that operative room lights be turned off during analysis

- Blood in the operating field and debris may interfere with spectroscopy

\section{Optical Coherence Tomography}

Optical coherence tomography (OCT) is a well-established medical imaging technique for obtaining cross-sectional microscopic images of biological tissues such as the retina. Its use has been rigorously investigated in several medical disciplines, including ophthalmology, dermatology, gastroenterology, and others. The practicality of obtaining high-resolution cross sectional images with no risk of tissue damage has made its use in ophthalmology routine for evaluation of the retina at a microscopic scale. ${ }^{58-60}$ Its functional and imaging concepts are similar to an ultrasound, with the difference being that it uses light instead of sound reflection to visualize structures at varying depths in the tissue.

Unlike other methods that offer optical slices in a plane parallel to the tissue (en-face), the attractiveness of this method lies in its inherent ability to provide deep cross-sections of the 
tissue (1-2mm) ${ }^{61}$ This is achieved by using long wavelength light, such as infrared light for imaging. OCT also does not require the addition of contrast material or preparation of the tissues because it uses the native refractive properties of the tissue. Unfortunately, standard OCT produces images at a resolution of roughly 10 microns, which is not sufficient for adequate cellular detail, but can offer information such as disruption of myelinated axons at areas of malignant invasion, or identification of sheets of tumor cells versus normal brain. ${ }^{62}$

Studies investigating the utility of OCT in the brain showed the ability of spectral-domain OCT imaging to delineate gliomas (low and high grade) from normal brain. ${ }^{62}$ Multiple studies have also demonstrated the ability of OCT equipment to image tissue at a far working distance, allowing their integration into the optical path of surgical microscopes. ${ }^{62,63}$ OCT may also be integrated in neuroendoscopic probes for microscopic imaging during neuroendoscopy. ${ }^{64}$ Although most OCT methods demonstrated their ability to identify tumors (including low-grade and high-grade gliomas), they lacked sufficient resolution for identification of the normal brain infiltrated by individual malignant cells at the edges of the tumor cavity. ${ }^{62,63}$ However, detection of small areas of residual tumor at the edges of tumor cavity is possible using continuous imaging by integrating the OCT in the optical path of the surgical microscope for non-contact imaging. ${ }^{63}$

Nonetheless, tumoral hemorrhage can compromise the interpretability of this modality. ${ }^{63}$ Further studies are required to study the effectiveness of this method. The advantage of OCT over other methodologies is its ability to image at depths greater than $1 \mathrm{~mm}$. It has been shown that OCT may be used to identify subsurface foci of metastatic tumor (such as melanoma) ${ }^{65}$ (Fig. 5). Current developments in optical coherence tomography have allowed for improved imaging resolution ${ }^{66}$ and expanded the area of imaged surfaces. ${ }^{67,68}$ Further OCT advances include the refinement of micro OCT technologies that allow the imaging of subcellular structures. ${ }^{69}$

\section{Advantages of OCT:}

- Provides cross-sectional morphologic assessment at a resolution of 10microns

- Does not require addition of contrast materials

- Utilizes near infrared or infrared light source with no risk of tissue damage

- Performs images at a distance and can therefore be integrated into surgical microscopes

- Similarly, may also be integrated into rigid endoscopic probes

- Imaging depths of more that $1 \mathrm{~mm}$ exceed those of fluorescent methods

- Automated OCT and full-field OCT allow for scanning of large fields of view at a microscopic level

\section{Disadvantages of OCT}


- Lacks sufficient cellular detail for detection of infiltrating malignant tumor cells at tumor margins

- Interference from extraneous operative light can be problematic

- Cannot visualize optically opaque tissues or tissues beyond an opaque barrier

\section{Multiphoton Microscopy}

Multiphoton imaging, including two photon imaging, has the advantages of imaging tissue at greater depths than traditional confocal (linear) microscopy and the ability to excite endogenous fluorophores with a fraction of the energy compared with standard fluorescence imaging modalities. ${ }^{70}$ Fluorescence imaging of brain tissue without the addition of contrast agents is possible with the aid of endogenous fluorophores such as NADPH, porphyrins, flavins, collagen, elastin, and lipofuscin. The inherent limitation of using endogenous autofluorescence is that the endogenous fluorophores are present at relatively low concentrations and require highintensity fluorescence excitation for imaging. At such high-intensity requirement, traditional fluorescence microscopy using a continuous light beam may result in tissue damage.

Multiphoton imaging utilizes femtosecond-pulsed lasers. Using short pulses of lasers maximizes the intensity of light used without impacting cell viability. These devices have excellent resolving power in normal and abnormal brain tissue without the addition of exogenous contrast materials ${ }^{71,72}$ (Fig 6b). In a study by Leppert et al., ex vivo multiphoton imaging provided identification of single malignant cells permeating normal brain at the tumor margins (Fig 6a). This imaging modality has been miniaturized and incorporated into prototype endoscopes currently being evaluated in the basic sciences. Though not yet studied in brain in vivo, these endoscopes have potential for neurosurgical utility. ${ }^{73,74}$

\section{Advantages of multiphoton microscopy:}

- High sensitivity and specificity with good discriminatory ability in the brain and high cellular resolution

- Allows delivery of high-intensity excitation pulses without photodamage

- Allows fluorescent imaging of endogenous fluorophores (autofluorescence), therefore no exogenous contrast material needed

- Can be integrated with other imaging modalities, such as fluorescent lifetime microscopy to increase imaging specificity and sensitivity

- Can be integrated in endoscopic and hand-held probes

\section{Limitations of multiphoton microscopy:}

- Technically demanding microscopy method that may not be easily integrated in neurosurgical equipment 
- Slower imaging acquisition rate

- limited by movements such as pulsation that introduce motion artifacts

\section{Fluorescence lifetime microscopy (FLIM)}

Traditional fluorescence imaging observations measure properties such as fluorescent intensity and frequency. An additional observable dimension is fluorescence lifetime and may add valuable information about molecular composition. Fluorescence lifetime is the average amount of fluorescence decay once a fluorophore is excited, and typically occurs within 100 nanoseconds. This lifetime is proportional to the quantity of excited fluorophores. The advantage of measuring fluorescence lifetime instead of fluorescence intensity is that two different molecules at different concentrations may emit the same fluorescence intensity; however, one may have a longer lifetime and can therefore be identified.

In order to measure the fluorescence lifetime; a laser pulse excites the specimen and starts a "stopwatch". Contrast is generated by analysis of decay times within sampled areas, allowing for spatial mapping and image construction. FLIM offers high sensitivity with only a few fluorophore molecules required for detection. This allows for low excitation intensity, preserving viability of specimens under lengthy observations. FLIM may therefore be added to complement most fluorescence modalities, including confocal and multiphoton microscopy and macroscopic fluorescent imaging. FLIM has been miniaturized for endoscopic large area imaging with development of a clinical instrument on the horizon. ${ }^{75}$

FLIM has been utilized reliably to differentiate glioma cell lines based on distinct endogenous fluorophore lifetime profiles compared with other tumor cell lines. ${ }^{71}$ Importantly, FLIM offers good delineation between gliomas and normal brain with the ability to resolve single malignant cells in the background of normal brain at the diffuse edges of glioma without the addition of any exogenous contrast material. ${ }^{71}$

FLIM combined with multiphoton imaging generates additional contrast between normal and neoplastic brain. The pulsed light sources utilized for multiphoton imaging allow integration of fluorescent lifetime measurement as a fourth and additional dimension..$^{71,72,76}$ This provides additional contrast between tumor and normal brain, ${ }^{76}$ and may be utilized to improve the contrast of exogenous fluorophores such as protoporphyrin IX. ${ }^{76}$

\section{Advantages of FLIM:}

- High-resolution imaging in combination with multiphoton and confocal imaging

- Does not require the addition of contrast materials

- Low energy delivered to tissue

- May generate contrast between cancer-specific molecules that may be overlooked via standard fluorescence 
- Combination with conventional macroscopic fluorescence imaging and endoscopy allows for FLIM imaging of large areas of tissues.

\section{Disadvantages of FLIM}

- High cost of instrumentation

- Slow image-acquisition rate

- Commercial device not currently available

\section{Mass Spectrometry}

Mass spectrometry is an analytical technique that sorts ions and small molecules based on their charge and mass. ${ }^{77}$ Different mass spectrometry techniques have been applied intraoperatively to guide surgical resection of tumors. These methods rely on the analysis of ionized gas produced from the electro-dissection or laser ablation; different signature patterns of molecular composition between normal and abnormal tissues are then determined.

The utility of mass spectrometry in tumor resection has been demonstrated in oncologic surgery. ${ }^{78,79}$ In one study, a vacuum is integrated with the electro-dissection instrument to allow a constant stream of vaporized gas to be analyzed in real-time. The premise of its use in the brain is based on the fact that certain onco-metabolites such as 2-hydroxyglutarate (2-HG) are produced by the tumor cells and are otherwise at extremely low concentrations within normal tissues. ${ }^{80}$ Of note, 2-HG is also a surrogate for IDH mutations, adding to the value of this method in determining the presence of this mutation. ${ }^{81,82}$ In addition to analysis of a single or multiple metabolites, complex protein and molecule patterns produced from analysis of different tissues differentiate normal and diseased tissues. ${ }^{83,84}$

Interestingly, metabolite profiles are able to distinguish between primary glioma subtypes, predict transformation and trajectories of low-grade and high-grade gliomas. ${ }^{85}$ In one study examining the intraoperative use of mass spectrometry, ${ }^{84}$ samples from biopsied sites were placed on a slide and then analyzed using mass spectrometry. No prior preparation of tissue was required otherwise. The results were then mapped stereotactically based on their biopsy site, allowing for surgical guidance. Another method has the ability to directly analyze ultrasonically liquefied brain tissue for real-time analysis at their primary site. ${ }^{86}$ These methods have been tested in ex vivo specimens, further studies are required to test their feasibility for direct in-vivo intraoperative use and accuracy.

\section{Advantages:}

- Fast analysis of tissues allowing accurate identification of diagnostic molecular profiles

- Allows detection of molecular changes within tumors such as IDH-1 mutations

- Does not require staining or preparation of tissues 


\section{Disadvantages:}

- Analysis requires vaporization or liquefaction of tissue

- Metabolite profiles for different tumors need to be established as a reference

- Method is not practical for examination of large areas of tissue

\section{Multimodal Microscopy}

Multimodal confocal reflectance and fluorescence microscopy: Confocal microscopy that simultaneously combines both reflectance and fluorescence modes provides complimentary information and enhances the diagnostic ability of both imaging techniques. Current benchtop confocal microscopes offer imaging in both reflectance and fluorescence modes. As described previously, each mode offers advantages and when combined together, the diagnostic ability of this form of microscopy is brought one step closer to resembling standard histology.

In general, reflectance mode is useful for assessing tumor architecture ${ }^{87,88}$ while fluorescence mode provides better cytological detail. ${ }^{87,88}$ Two separate studies examined ex vivo brain tumor samples in both reflectance and fluorescence modes using different microscopes. Combination of the confocal modes still required the addition of a fluorescent contrast agent and allowed easy identification of meningiomas that demonstrate recognizable whorling patterns appreciated via reflectance and nuclear details such as pseudo-inclusions appreciated via fluorescence $^{88}$ (Fig. 7). Combining confocal modes allowed identification of essential diagnostic criteria such as cellularity, vascularity, necrosis, and infiltration; however, mitoses were not identifiable. ${ }^{87}$

Distinguishing white and gray matter is possible with a very high degree of certainty via combination of fluorescence and reflectance microscopy ${ }^{17}$. On reflectance mode, gray matter has a finely granular appearance while white matter shows thicker "cotton-like" appearance. The addition of fluorescence demonstrates lower cellularity in white matter. ${ }^{17}$ Low-grade gliomas that offer only subtle changes in cellularity and cytologic atypia are more challenging to diagnose using fluorescence alone. Interestingly, reflectance images show a different structural pattern in low grade gliomas that are distinguishable from normal brain. ${ }^{17,88}$ This structural lattice formed by cellular processes, not visualized in standard hematoxylin and eosin stained tissues, complements the diagnostic utility of this method. ${ }^{88}$ This pattern is especially useful if the cellularity and other cytological features are not completely diagnostic of a low-grade glioma. ${ }^{88}$

Also, absence of the glial meshwork on reflectance mode may suggest a non-glial or metastatic tumor. ${ }^{17}$ Multimodal confocal microscopy therefore combines the advantages of both reflectance and fluorescent microscopy. It offers a high sensitivity and specificity for detecting normal versus abnormal brain tissue, $95 \%$ and $100 \%$, respectively. ${ }^{17}$ An additional advantage of multimodal confocal reflectance and fluorescence microscopy is the ability of pseudocoloring to 
produce images that resemble hematoxylin and eosin stains. Pseudocoloring fluorescence images in blue and reflectance in pink generate images that closely resemble hematoxylin and eosin stained histology. Unfortunately, this modality is yet to be miniaturized for practical clinical use.

\section{Multimodal two-photon microscopy combined with coherent anti-stokes Raman} spectroscopy (CARS): Combination of two-photon microscopy and Raman spectroscopy for potential intraoperative diagnosis of brain tumors has been studied. ${ }^{89}$ This method most likely provides the best imaging quality in comparison with standard histology without the addition of contrast agents. The addition of Raman spectroscopy enhances the structural contrast. Structures rich in fatty acids provide strong intensity signals and allow good nuclear membrane and cytological delineation when mapped in correspondence to images produced using two photon microscopy (Fig. 8).

Necrosis is especially easier to identify due to the sensitivity of Raman spectroscopy for detecting cholesterol rich necrotic zones. The two-photon microscopy component provides adequate cytological and nuclear detail without the aid of fluorescent agents (Fig. 8). Further studies are required to determine the accuracy of this method and comparison with other methods. One significant limitation of this method is the time required for acquisition. A single image requires approximately 30 seconds, which results in imaging times of around 2 hours if an imaging mosaic of a large area is obtained. Miniaturization of this method is not currently available for practical integration in neurosurgery. ${ }^{89}$

Pertinent studies of in-vivo imaging in neurosurgical oncology are summarized in Table 1. Technical comparisons among different imaging modalities are reviewed in Table 2.

\section{CONCLUSIONS}

The advent of clinical molecular imaging has provided a unique means to obtain realtime histopathologic images of tumors and their microenvironments. Multiple technical advancements have allowed direct real-time molecular evaluation of brain tissue, providing a practical approach to enhancing the extent of tumor resection. Moreover, some of the more useful technologies have not been yet readily integrated into the operating instrumentation.

Currently, flexible and miniaturized confocal microscopy (LSCE) as well as Raman spectroscopy are among the most researched and utilized in neurosurgical oncology. In our opinion, miniaturization and customization of multi-modal imaging technologies for neurosurgical application may have the greatest potential for practical clinical application. Additionally, the use of imaging modalities that do not require the addition of contrast agents may increase adoptability and research. However, further technical advances, are still required to 
improve acquisition rates, cost, and the ability to integrate these methods into neurosurgical procedures.

One of the basic limitations of most in vivo microscopic methods is their inability to practically and conveniently scan large areas of tissue at various magnifications. Development of larger area scanning methods for targeting areas of interest may further improve the practicality of in vivo microscopy. Unfortunately, most of the modalities discussed herein have been investigated only on ex vivo specimens. Imaging in vivo introduces challenges from motion artifact and bleeding interference that make interpretation of images more challenging. Additionally, in vivo and real-time mass spectrometry and Raman spectroscopy already have the potential to provide immediate molecular information intraoperatively. Arguably, accurate pathological diagnosis may not be the aim of in vivo microscopy and rather an accurate distinction between normal and abnormal tissues is sufficient. Large multi-center clinical trials involving neurosurgeons and neuropathologists are therefore needed to validate the currently well established in-vivo imaging technologies for identification of residual tumor within tumor beds.

In vivo microscopy is an emerging clinical tool which can provide neurosurgeons and neuropathologists real-time intraoperative histologic information. This technology is under development with the goal of providing clinicians with immediate information for differentiating tumors from normal brain, and possibly providing immediate histopathologic diagnoses. These techniques will continue to evolve and those with the greatest clinical utility will be elucidated. 


\section{REFERENCES}

1. Hardesty DA, Sanai N. The value of glioma extent of resection in the modern neurosurgical era. Frontiers in neurology. 2012;3:140.

2. Sanai N, Berger MS. Glioma extent of resection and its impact on patient outcome. Neurosurgery. 2008;62(4):753-764; discussion 264-756.

3. McGirt MJ, Chaichana KL, Gathinji M, et al. Independent association of extent of resection with survival in patients with malignant brain astrocytoma. Journal of neurosurgery. 2009;110(1):156162.

4. Stummer W, Pichlmeier U, Meinel T, Wiestler OD, Zanella F, Reulen HJ. Fluorescence-guided surgery with 5-aminolevulinic acid for resection of malignant glioma: a randomised controlled multicentre phase III trial. The Lancet Oncology. 2006;7(5):392-401.

5. Li-Feng $\mathrm{C}$, Yang $\mathrm{Y}$, Xiao-Dong $\mathrm{M}$, et al. Optimizing the Extent of Resection and Minimizing the Morbidity in Insular High-Grade Glioma Surgery by High-Field Intraoperative MRI Guidance. Turkish neurosurgery. 2016.

6. Sanai N, Martino J, Berger MS. Morbidity profile following aggressive resection of parietal lobe gliomas. Journal of neurosurgery. 2012;116(6):1182-1186.

7. McGirt MJ, Mukherjee D, Chaichana KL, Than KD, Weingart JD, Quinones-Hinojosa A. Association of surgically acquired motor and language deficits on overall survival after resection of glioblastoma multiforme. Neurosurgery. 2009;65(3):463-469; discussion 469-470.

8. Huber A, Beran H, Becherer A, Prosenc N, Witzmann A. [Supratentorial glioma: analysis of clinical and temporal parameters in 163 cases]. Neurochirurgia. 1993;36(6):189-193.

9. Watts C, Sanai N. Surgical approaches for the gliomas. Handbook of clinical neurology. 2016;134:51-69.

10. Burger PC, Vogel FS. Frozen section interpretation in surgical neuropathology. II. Intraspinal lesions. The American journal of surgical pathology. 1978;2(1):81-95.

11. Burger PC. Use of cytological preparations in the frozen section diagnosis of central nervous system neoplasia. The American journal of surgical pathology. 1985;9(5):344-354.

12. Cahill EM, Hidvegi DF. Crush preparations of lesions of the central nervous system. A useful adjunct to the frozen section. Acta cytologica. 1985;29(3):279-285.

13. Moriya J, Tanino MA, Takenami T, et al. Rapid immunocytochemistry based on alternating current electric field using squash smear preparation of central nervous system tumors. Brain tumor pathology. 2016;33(1):13-18.

14. Pavlova I, Hume KR, Yazinski SA, et al. Multiphoton microscopy and microspectroscopy for diagnostics of inflammatory and neoplastic lung. BIOMEDO. 2012;17(3):0360141-0360149.

15. Leppert J, Krajewski J, Kantelhardt SR, et al. Multiphoton excitation of autofluorescence for microscopy of glioma tissue. Neurosurgery. 2006;58(4):759-767.

16. Pierce MC, Schwarz RA, Bhattar VS, et al. Accuracy of in vivo multimodal optical imaging for detection of oral neoplasia. Cancer Prevention Research. 2012;5(6):801-809.

17. Snuderl $M$, Wirth $D$, Sheth $S A$, et al. Dye-enhanced multimodal confocal imaging as a novel approach to intraoperative diagnosis of brain tumors. Brain Pathol. 2013;23(1):73-81.

18. Wang KK, Carr-Locke DL, Singh SK, et al. Use of probe-based confocal laser endomicroscopy ( $p C L E$ ) in gastrointestinal applications. A consensus report based on clinical evidence. United European gastroenterology journal. 2015;3(3):230-254.

19. Wallace M, Lauwers GY, Chen Y, et al. Miami classification for probe-based confocal laser endomicroscopy. Endoscopy. 2011;43(10):882-891.

20. Foersch S, Heimann A, Ayyad A, et al. Confocal laser endomicroscopy for diagnosis and histomorphologic imaging of brain tumors in vivo. PloS one. 2012;7(7):e41760. 
21. Martirosyan NL, Eschbacher JM, Kalani MY, et al. Prospective evaluation of the utility of intraoperative confocal laser endomicroscopy in patients with brain neoplasms using fluorescein sodium: experience with 74 cases. Neurosurgical focus. 2016;40(3):E11.

22. Peyre M, Clermont-Taranchon E, Stemmer-Rachamimov A, Kalamarides M. Miniaturized handheld confocal microscopy identifies focal brain invasion in a mouse model of aggressive meningioma. Brain Pathol. 2013;23(4):371-377.

23. Fleischhauer K. [Fluorescence microscopy studies on the glial fibers. I. Observations on the walls of the cerebral ventricles of the cat (lateral ventricle, third ventricle)]. Z Zellforsch Mikrosk Anat. 1960;51:467-496.

24. Fidel J, Kennedy KC, Dernell WS, et al. Preclinical Validation of the Utility of BLZ-100 in Providing Fluorescence Contrast for Imaging Spontaneous Solid Tumors. Cancer research. 2015;75(20):4283-4291.

25. Hutteman M, Mieog JSD, van der Vorst JR, et al. Randomized, double-blind comparison of indocyanine green with or without albumin premixing for near-infrared fluorescence imaging of sentinel lymph nodes in breast cancer patients. Breast cancer research and treatment. 2011;127(1):163-170.

26. van der Vorst JR, Schaafsma BE, Verbeek FP, et al. Randomized comparison of near-infrared fluorescence imaging using indocyanine green and $99 \mathrm{~m}$ technetium with or without patent blue for the sentinel lymph node procedure in breast cancer patients. Annals of surgical oncology. 2012;19(13):4104-4111.

27. Kuroda $\mathrm{K}$, Kinouchi $\mathrm{H}$, Kanemaru $\mathrm{K}$, et al. Intra-arterial injection fluorescein videoangiography in aneurysm surgery. Operative Neurosurgery. 2013;72:ons141-ons150.

28. Shin D, Vigneswaran N, Gillenwater A, Richards-Kortum R. Advances in fluorescence imaging techniques to detect oral cancer and its precursors. Future Oncology. 2010;6(7):1143-1154.

29. Nguyen QT, Tsien RY. Fluorescence-guided surgery with live molecular navigation [mdash] a new cutting edge. Nature reviews cancer. 2013;13(9):653-662.

30. Vercauteren T, Doussoux F, Cazaux M, et al. Multicolor probe-based confocal laser endomicroscopy: a new world for in vivo and real-time cellular imaging. Paper presented at: SPIE BiOS2013.

31. Charalampaki P, Javed M, Daali S, Heiroth HJ, Igressa A, Weber F. Confocal Laser Endomicroscopy for Real-time Histomorphological Diagnosis: Our Clinical Experience With 150 Brain and Spinal Tumor Cases. Neurosurgery. 2015;62 Suppl 1:171-176.

32. W HC. Picture transmission. Google Patents; 1930.

33. Pavlov V, Meyronet D, Meyer-Bisch V, et al. Intraoperative Probe-Based Confocal Laser Endomicroscopy in Surgery and Stereotactic Biopsy of Low-Grade and High-Grade Gliomas: A Feasibility Study in Humans. Neurosurgery. 2016;79(4):604-612.

34. Breuskin D, Divincenzo J, Kim YJ, Urbschat S, Oertel J. Confocal laser endomicroscopy in neurosurgery: a new technique with much potential. Minimally invasive surgery. 2013;2013:851819.

35. Han JH, Lee J, Kang JU. Pixelation effect removal from fiber bundle probe based optical coherence tomography imaging. Optics express. 2010;18(7):7427-7439.

36. Ackerman LV, Ramirez GA. The indications for and limitations of frozen section diagnosis; a review of 1269 consecutive frozen section diagnoses. The British journal of surgery. 1959;46(198):336-350.

37. Webb RH. Confocal optical microscopy. Reports on Progress in Physics. 1996;59(3):427.

38. Richards-Kortum R, Drezek R, Smithpeter C, Zuluaga AF. Acetic acid as a contrast in reflectance confocal imaging of tissue. Google Patents; 2001. 
39. Collier T, Shen $\mathrm{P}$, de Pradier B, et al. Near real time confocal microscopy of amelanotic tissue: dynamics of aceto-whitening enable nuclear segmentation. Optics express. 2000;6(2):40-48.

40. White WM, Rajadhyaksha M, Gonzalez S, Fabian RL, Anderson RR. Noninvasive imaging of human oral mucosa in vivo by confocal reflectance microscopy. The Laryngoscope. 1999;109(10):1709-1717.

41. Drezek RA, Collier T, Brookner CK, et al. Laser scanning confocal microscopy of cervical tissue before and after application of acetic acid. American journal of obstetrics and gynecology. 2000;182(5):1135-1139.

42. Rajadhyaksha M, Gonzalez S, Zavislan JM. Detectability of contrast agents for confocal reflectance imaging of skin and microcirculation. J Biomed Opt. 2004;9(2):323-331.

43. Mooney MA, Georges J, Yazdanabadi MI, et al. Immediate ex-vivo diagnosis of pituitary adenomas using confocal reflectance microscopy: a proof-of-principle study. Journal of neurosurgery. 2017:1-4.

44. Georges J, Zehri A, Carlson E, et al. Label-free microscopic assessment of glioblastoma biopsy specimens prior to biobanking. Neurosurgical focus. 2014;36(2):E8.

45. Liang C, Descour M, Sung KB, Richards-Kortum R. Fiber confocal reflectance microscope (FCRM) for in-vivo imaging. Optics express. 2001;9(13):821-830.

46. Maitland KC, Gillenwater AM, Williams MD, El-Naggar AK, Descour MR, Richards-Kortum RR. In vivo imaging of oral neoplasia using a miniaturized fiber optic confocal reflectance microscope. Oral oncology. 2008;44(11):1059-1066.

47. Smith E, Dent G. Modern Raman spectroscopy: a practical approach. John Wiley \& Sons; 2013.

48. Mizuno A, Hayashi T, Tashibu K, Maraishi S, Kawauchi K, Ozaki Y. Near-infrared FT-Raman spectra of the rat brain tissues. Neuroscience letters. 1992;141(1):47-52.

49. Koljenovic S, Choo-Smith LP, Bakker Schut TC, Kros JM, van den Berge HJ, Puppels GJ.

Discriminating vital tumor from necrotic tissue in human glioblastoma tissue samples by Raman spectroscopy. Laboratory investigation; a journal of technical methods and pathology. 2002;82(10):1265-1277.

50. Mizuno A, Kitajima H, Kawauchi K, Muraishi S, Ozaki Y. Near-infrared Fourier transform Raman spectroscopic study of human brain tissues and tumours. Journal of Raman Spectroscopy. 1994;25(1):25-29.

51. Krafft C, Neudert L, Simat T, Salzer R. Near infrared Raman spectra of human brain lipids. Spectrochimica acta Part A, Molecular and biomolecular spectroscopy. 2005;61(7):1529-1535.

52. Shankar GM, Francis JM, Rinne ML, et al. Rapid Intraoperative Molecular Characterization of Glioma. JAMA oncology. 2015;1(5):662-667.

53. Krafft C, Kirsch M, Beleites C, Schackert G, Salzer R. Methodology for fiber-optic Raman mapping and FTIR imaging of metastases in mouse brains. Analytical and bioanalytical chemistry. 2007;389(4):1133-1142.

54. Beljebbar A, Dukic S, Amharref N, Manfait M. Ex vivo and in vivo diagnosis of $\mathrm{C} 6$ glioblastoma development by Raman spectroscopy coupled to a microprobe. Analytical and bioanalytical chemistry. 2010;398(1):477-487.

55. Jermyn M, Mok K, Mercier J, et al. Intraoperative brain cancer detection with Raman spectroscopy in humans. Science translational medicine. 2015;7(274):274ra219.

56. Ji M, Lewis S, Camelo-Piragua S, et al. Detection of human brain tumor infiltration with quantitative stimulated Raman scattering microscopy. Science translational medicine. 2015;7(309):309ra163.

57. Freudiger CW, Pfannl R, Orringer DA, et al. Multicolored stain-free histopathology with coherent Raman imaging. Laboratory investigation; a journal of technical methods and pathology. 2012;92(10):1492-1502. 
58. Karl A, Stepp H, Willmann E, et al. Optical coherence tomography for bladder cancer -- ready as a surrogate for optical biopsy? Results of a prospective mono-centre study. European journal of medical research. 2010;15(3):131-134.

59. Puliafito CA, Hee MR, Lin CP, et al. Imaging of macular diseases with optical coherence tomography. Ophthalmology. 1995;102(2):217-229.

60. Daniltchenko D, Konig F, Lankenau E, et al. [Utilizing optical coherence tomography (OCT) for visualization of urothelial diseases of the urinary bladder]. Der Radiologe. 2006;46(7):584-589.

61. Fercher AF, Drexler W, Hitzenberger CK, Lasser T. Optical coherence tomography-principles and applications. Reports on progress in physics. 2003;66(2):239.

62. Giese A, Böhringer H, Leppert J, et al. Non-invasive intraoperative optical coherence tomography of the resection cavity during surgery of intrinsic brain tumors. Paper presented at: Biomedical Optics 20062006.

63. Bohringer HJ, Lankenau E, Stellmacher F, Reusche E, Huttmann G, Giese A. Imaging of human brain tumor tissue by near-infrared laser coherence tomography. Acta neurochirurgica. 2009;151(5):507-517; discussion 517.

64. Bohringer HJ, Lankenau E, Rohde V, Huttmann G, Giese A. Optical coherence tomography for experimental neuroendoscopy. Minimally invasive neurosurgery : MIN. 2006;49(5):269-275.

65. Boppart SA, Brezinski ME, Pitris C, Fujimoto JG. Optical coherence tomography for neurosurgical imaging of human intracortical melanoma. Neurosurgery. 1998;43(4):834-841.

66. Bizheva $K$, Unterhuber A, Hermann B, et al. Imaging ex vivo and in vitro brain morphology in animal models with ultrahigh resolution optical coherence tomography. BIOMEDO. 2004;9(4):719-724.

67. Finke M, Kantelhardt S, Schlaefer A, et al. Automatic scanning of large tissue areas in neurosurgery using optical coherence tomography. The international journal of medical robotics + computer assisted surgery : MRCAS. 2012;8(3):327-336.

68. Assayag $\mathrm{O}$, Grieve $\mathrm{K}$, Devaux B, et al. Imaging of non-tumorous and tumorous human brain tissues with full-field optical coherence tomography. Neurolmage Clinical. 2013;2:549-557.

69. Liu L, Gardecki JA, Nadkarni SK, et al. Imaging the subcellular structure of human coronary atherosclerosis using micro-optical coherence tomography. Nature medicine. 2011;17(8):10101014.

70. Zipfel WR, Williams RM, Webb WW. Nonlinear magic: multiphoton microscopy in the biosciences. Nature biotechnology. 2003;21(11):1369-1377.

71. Leppert J, Krajewski J, Kantelhardt SR, et al. Multiphoton excitation of autofluorescence for microscopy of glioma tissue. Neurosurgery. 2006;58(4):759-767; discussion 759-767.

72. Kantelhardt SR, Leppert J, Krajewski J, et al. Imaging of brain and brain tumor specimens by time-resolved multiphoton excitation microscopy ex vivo. Neuro-oncology. 2007;9(2):103-112.

73. Liu G, Kieu K, Wise FW, Chen Z. Multiphoton microscopy system with a compact fiber-based femtosecond-pulse laser and handheld probe. Journal of biophotonics. 2011;4(1-2):34-39.

74. Duan X, Li H, Qiu Z, et al. MEMS-based multiphoton endomicroscope for repetitive imaging of mouse colon. Biomedical optics express. 2015;6(8):3074-3083.

75. Sparks H, Warren S, Guedes J, et al. A flexible wide-field FLIM endoscope utilising blue excitation light for label-free contrast of tissue. Journal of biophotonics. 2015;8(1-2):168-178.

76. Kantelhardt SR, Diddens H, Leppert J, Rohde V, Huttmann G, Giese A. Multiphoton excitation fluorescence microscopy of 5-aminolevulinic acid induced fluorescence in experimental gliomas. Lasers in surgery and medicine. 2008;40(4):273-281.

77. De Hoffmann E, Stroobant V. Mass spectrometry: principles and applications. John Wiley \& Sons; 2007. 
78. Balog J, Sasi-Szabo L, Kinross J, et al. Intraoperative tissue identification using rapid evaporative ionization mass spectrometry. Science translational medicine. 2013;5(194):194ra193.

79. Sachfer KC, Szaniszlo T, Gunther S, et al. In situ, real-time identification of biological tissues by ultraviolet and infrared laser desorption ionization mass spectrometry. Analytical chemistry. 2011;83(5):1632-1640.

80. Santagata S, Eberlin LS, Norton I, et al. Intraoperative mass spectrometry mapping of an oncometabolite to guide brain tumor surgery. Proceedings of the National Academy of Sciences of the United States of America. 2014;111(30):11121-11126.

81. Ward PS, Patel J, Wise DR, et al. The common feature of leukemia-associated IDH1 and IDH2 mutations is a neomorphic enzyme activity converting alpha-ketoglutarate to 2hydroxyglutarate. Cancer cell. 2010;17(3):225-234.

82. Dang L, White DW, Gross S, et al. Cancer-associated IDH1 mutations produce 2hydroxyglutarate. Nature. 2009;462(7274):739-744.

83. Chaurand $P$, Schwartz SA, Caprioli RM. Assessing protein patterns in disease using imaging mass spectrometry. Journal of proteome research. 2004;3(2):245-252.

84. Agar NY, Golby AJ, Ligon KL, et al. Development of stereotactic mass spectrometry for brain tumor surgery. Neurosurgery. 2011;68(2):280-289; discussion 290.

85. Elkhaled A, Jalbert L, Constantin A, et al. Characterization of metabolites in infiltrating gliomas using ex vivo (1) $\mathrm{H}$ high-resolution magic angle spinning spectroscopy. NMR in biomedicine. 2014;27(5):578-593.

86. Schafer KC, Balog J, Szaniszlo T, et al. Real time analysis of brain tissue by direct combination of ultrasonic surgical aspiration and sonic spray mass spectrometry. Analytical chemistry. 2011;83(20):7729-7735.

87. Forest F, Cinotti E, Yvorel V, et al. Ex vivo confocal microscopy imaging to identify tumor tissue on freshly removed brain sample. Journal of neuro-oncology. 2015;124(2):157-164.

88. Wirth $D$, Snuderl $M$, Sheth $S$, et al. Identifying brain neoplasms using dye-enhanced multimodal confocal imaging. J Biomed Opt. 2012;17(2):026012.

89. Romeike BF, Meyer T, Reichart R, et al. Coherent anti-Stokes Raman scattering and two photon excited fluorescence for neurosurgery. Clinical neurology and neurosurgery. 2015;131:42-46. 


\section{Figure Legends}

Figure 1: a: fiberoptic probe with emitting blue light to be placed on tissue of interest for in-vivo imaging. b: Confocal image obtained through flexible fiber-optic probe demonstrating a Rosenthal fiber within a pilocytic astrocytoma. The pilocytic astrocytoma also displays the typical spider-web structure. Reproduced with permission: Charalampaki P, Javed M, Daali S, Heiroth HJ, Igressa A, Weber F: Confocal laser endomicroscopy for real-time histomorphological diagnosis: our clinical experience with 150 brain and spinal tumor cases. Neurosurgery 62 Suppl 1:171-176, 201, by permission of, Congress of Neurological Surgeons, Oxford University Press, provided by Oxford University Press and Copyright Clearance Center.

Figure 2: Images acquired using rigid probe confocal microscope. a: image of glioblastoma showing diffuse growth with indistinguishable cellular borders, high nuclear cellularity (white spots) and nuclear pleomorphism . b: image of a psammomatous meningioma with multiple, round, hypo-fluorescent psammoma bodies. ${ }^{34}$ Reproduced with permission from Breuskin D, Divincenzo J, Kim YJ, Urbschat S, Oertel J: Confocal laser endomicroscopy in neurosurgery: a new technique with much potential. Minim Invasive Surg 2013:851819, 2013

Figure 3.Images and setup using miniaturized confocal laser endomicroscope. a: A miniaturized confocal laser endomicroscopy setup in anesthesized tumor-bearing rats b: A- Gross view of intracranial windows, transition zone between health brain and tumor seen in circle on the left side. B; appearance of vessels after intravenous injection of FITC-dextran showing massive extravasation, and 'bleeding' of fluorescence in interstitial zones. C,D; normal vessel morphology with no extravasation following injection of FITC-Dextran. E; Histologic appearance of transition zone with cellular tumor on the right. G; in-vivo appearance of transition zone with cellular tumor on the right. ${ }^{20}$ Reproduced with permission: Foersch $\mathrm{S}$, Heimann A, Ayyad A, Spoden GA, Florin L, Mpoukouvalas K, et al: Confocal laser endomicroscopy for diagnosis and histomorphologic imaging of brain tumors in vivo. PLoS One 7:e41760, 2012

Figure 4: a: Images and setup of in-vivo Raman spectroscopy. (A) Raman spectroscopy setup with Raman probe and high-resolution CCD spectroscopic detector resulting in waveforms specific to different tissue types. (B)Raman spectroscopy probe used in-vivo, schematic diagrams illustrates excitation of molecules resulting in waveforms specific to different molecular species aiding diagnosis. ${ }^{55}$ From Jermyn M, Mok K, Mercier J, Desroches J, Pichette $J$, Saint-Arnaud K, et al: Intraoperative brain cancer detection with Raman spectroscopy in humans. Sci Transl Med 7:274ra219, 2015. Reprinted with permission from AAAS. b: (A) MRI showing glioblastoma with ring enhancement (arrowhead) (B)Nuclear crowding and pleomorphism seen in both stimulated raman spectroscopy (SRS) (left) and hematoxylin \& eosin (H\&E) (right) microscopy. (C) vascular proliferation demonstrated as tortuous vassels on SRS microscopy (left, arrowheads) and with periodic acid Schiff staining (right, arrowhead). (D) Mitotic figures are visible (arrowheads) with SRS microscopy (left) and H\&E staining (right). (E and F) Non-enhancing, low-grade oligodendroglioma (arrowhead, E) consists of nested cellular tissue with "fried-egg" nuclearmorphology (arrowheads, F) causing minimal axonal disruption on SRS imaging (left), correlates with neurofilament immunostaining (right). (G and $\mathrm{H}$ ) "Chicken wire" blood vessels in oligodendroglioma (arrowheads, G) and perineuronal satellitosis is visible in both SRS and H\&E. From [Ji M, Lewis S, Camelo-Piragua S, Ramkissoon SH, 
Snuderl M, Venneti S, et al: Detection of human brain tumor infiltration with quantitative stimulated Raman scattering microscopy. Sci Transl Med 7:309ra163, 2015]. Reprinted with permission from AAAS

Figure 5. Optical coherence tomography cross-sectional imaging C-D; showing subsurface metastatic intracortical melanoma (arrow head) . E-F; corresponding histologic sections demonstrating subcortical metastatic melanoma. G; digital en-face mosaicing produced by stitching multiple crossectional images (lines A and B) allowing a topologic localization of subcortical metastatic melanoma ${ }^{65}$. Reproduced with permission from Boppart SA, Brezinski ME, Pitris C, Fujimoto JG: Optical coherence tomography for neurosurgical imaging of human intracortical melanoma. Neurosurgery 43:834-841, 199. By permission of, Oxford University Press; provided by Oxford University Press and Copyright Clearance Center.

Figure 6: Ex-vivo multiphoton microscopy if glioblastoma without the addition of exogenous contrast material. a shows the resection edge of the tumor composed of single invasive tumor cells (bright, larger cells) in a backgroud of normal brain. $b$ shows the cellular portion of the the glioblastoma composed of large, pleomorphic cells with bright cytoplasms. Reproduced with permission from Leppert J, Krajewski J, Kantelhardt SR, Schlaffer S, Petkus N, Reusche E, et al: Multiphoton excitation of autofluorescence for microscopy of glioma tissue. Neurosurgery 58:759-767; discussion 759-767, 2006. By permission of, Oxford University Press, provided by Oxford University Press and Copyright Clearance Center.

Fig 7: Multimodal confocal reflectance and fluorscence microscopy. a: Images of meningioma. (a) reflactance mode image showing fibrous outer layers of meningeal whorls (dashed arrows),

(b) fluorescence mode showing fluorescent meningeal cells arranged in nests (solid arrows), (c); corresponding hematoxylin and eosin-stained histologic section. Fig. 7(b); Images of low-grade astrocytoma. (a) reflectance mode showing blood vessel (dotted arrow) and disrupted neural network pattern. (b) fluorescence mode demonstrates glioma cells (solid arrows) with increased cellularity. (c) corresponding hematoxylin and eosin-stained histologic section. ${ }^{88}$ Reprodued with permission from Wirth D, Snuderl M, Sheth S, Kwon CS, Frosch MP, Curry W, et al: Identifying brain neoplasms using dye-enhanced multimodal confocal imaging. J Biomed Opt 17:026012, 2012.

Figure 8: Composite showing comparison of different tumors using standard Hematoxylin and Eosin, Two photon excited fluorescence (TPEF), coherent anti-Stokes raman scattering (CARS) and multimodal combination of TPEF and CARS. Images A-D, show metastasis of squamous cell carcinoma. TPEF and CARS highlight the boundaries of the architecture. Images E-H show a diffuse gilioma with moderate cellularity. TPEF demonstrates the cytological cellularity while CARS highlights the distorted architcural infrasturcure. Images I to L show the outer border of a lympha, with TPEF highluighting the vessels while CARS highlights the structureal detail. Images $\mathrm{M}$ to $\mathrm{P}$ show the central portion of the same lymphoma depicted in images I to $\mathrm{L}$, showing increased density. Scale bars A and E: 500 micrometers, All others 5o micrometers. Reproduced with permission from Romeike BF, Meyer T, Reichart R, Kalff R, Petersen I, Dietzek B, et al: Coherent anti-Stokes raman scattering and two photon excited fluorescence for neurosurgery. Clin Neurol Neurosurg 131:42-46, 2015. With permission from Elsevier; provided by Elsevier and Copyright Clearance Center.

Table 1: Summary of pertinent in-vivo microscopy studies for neurosurgical applications 
Table 2: Technical comparison between different imaging modalities 
Table 2: Technical comparison between different imaging modalities

\begin{tabular}{|c|c|c|c|c|c|}
\hline & $\begin{array}{l}\text { Depth of } \\
\text { images }\end{array}$ & $\begin{array}{l}\text { Contrast } \\
\text { agent used }\end{array}$ & Sensitivity & Specificity & $\begin{array}{l}\text { Current } \\
\text { apparatus for } \\
\text { Intraoperative } \\
\text { use available }\end{array}$ \\
\hline \begin{tabular}{l|l} 
L & Flexible \\
S & probe
\end{tabular} & $100 \mu \mathrm{m}$ & Yes & N/A & N/A & Yes*** \\
\hline $\begin{array}{l}\text { Rigid } \\
\text { E probe }\end{array}$ & $80 \mu \mathrm{m}^{10}$ & Yes & $\begin{array}{l}\text { Relatively Low } \\
* *\end{array}$ & Relatively Low** & No \\
\hline $\begin{array}{l}\text { Miniaturiz } \\
\text { ed }\end{array}$ & $250 \mu \mathrm{m}^{15}$ & Yes & $91 \% *^{53}$ & $94 \% *^{53}$ & Yes \\
\hline CRM & $\begin{array}{l}200-300 \\
\mu \mathrm{m}^{31}\end{array}$ & No & N/A & N/A & No \\
\hline FLIM & N/A & No & $\mathrm{N} / \mathrm{A}$ & N/A & No \\
\hline Multiphoton & $200 \mu \mathrm{m}$ & No & N/A & N/A & No \\
\hline OCT & $\begin{array}{l}\text { Up to } \\
1000 \mu \mathrm{m}\end{array}$ & No & Relatively Low & Relatively Low & Yes \\
\hline Raman & $25-80 \mu \mathrm{m}$ & No & $93 \%$ & $91 \%$ & Yes \\
\hline $\begin{array}{l}\text { Mass } \\
\text { Spectrometry }\end{array}$ & N/A & No & N/A & N/A & Yes \\
\hline $\begin{array}{l}\text { Multimodal } \\
\text { Fluorescence } \\
\text { and } \\
\text { reflectance }\end{array}$ & N/A & Yes & $95 \% * * * *$ & $100 \% * * * *$ & No \\
\hline $\begin{array}{l}\text { Multimodal } \\
\text { CARS and } \\
\text { two-photon } \\
\text { microscopy }\end{array}$ & N/A & No & N/A & N/A & No \\
\hline
\end{tabular}

Abbreviations: CARS: Coherent antistokes raman spectroscopy; CRM: Confocal Refelectance Microscopy; FLIM: Fluorescence lifetime microscopy; LSCE: Laser scanning confocal endomicroscopy; N/A: No sufficient data available; OCT: Optical coherence tomography

* Sensitivity and specificity rates for gliomas diagnoses using rigid probe LSCE, rates for meningioma are $93 \%$ and $97 \%$ respectively ${ }^{53}$.

** showed that rigid probe LSCE correctly identified $86 \%$ of gliomas, $78 \%$ of meningiomas but only 20\% of metastatic tumors: Abstract publication; David Breuskin JD, Yoo-Jin Kim, Steffi Urbschat, Joachim Oertel: Confocal laser endomicroscopy - a novel technique of diagnostics in neurosurgery? 64th Annual Meeting of the German Society of Neurosurgery (DGNC) 26 - 29, 2013 
***Flexible probes offer the smallest and most flexible form of miniaturization for possibly the most convenient and accessible imaging

**** Sensitivity and specificity values for detecting normal vs. abnormal brain tissue. 
Table 1: Summary of pertinent in-vivo microscopy studies for neurosurgical applications

\begin{tabular}{|c|c|c|c|c|c|}
\hline Method & $\begin{array}{l}\text { Authors, } \\
\text { year }\end{array}$ & Title & $\begin{array}{l}\text { Animal, } \\
\text { ex-vivo, } \\
\text { in-vivo }\end{array}$ & $\begin{array}{l}\text { Number of } \\
\text { specimens/pa } \\
\text { tients }\end{array}$ & Findings \\
\hline \multirow[b]{2}{*}{ 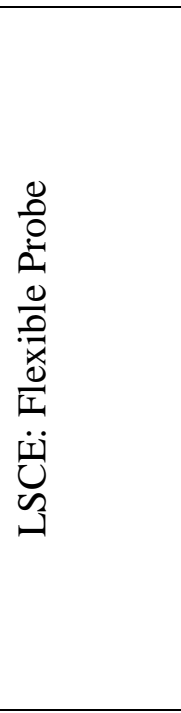 } & $\begin{array}{l}\text { Charalampa } \\
\text { ki P et al., } \\
2015\end{array}$ & $\begin{array}{l}\text { Endomicroscopy for real- } \\
\text { time histomorphologic } \\
\text { diagnosis: our clinical } \\
\text { experience with } 150 \text { brain } \\
\text { and spinal tumor cases }\end{array}$ & Ex-vivo & $\begin{array}{l}150 \\
\text { specimens }\end{array}$ & $\begin{array}{l}\text { Histologic features } \\
\text { were demonstrable } \\
\text { using the technique in } \\
\text { most brain primary and } \\
\text { metastatic tumor types. }\end{array}$ \\
\hline & $\begin{array}{l}\text { Pavlov V et } \\
\text { al., } 2016\end{array}$ & $\begin{array}{l}\text { Intraoperative probe-based } \\
\text { confocal laser } \\
\text { endomicroscopy in surgery } \\
\text { and stereotactic biopsy of } \\
\text { low-grade and high-grade } \\
\text { gliomas: a feasibility study } \\
\text { in humans }\end{array}$ & In-vivo & 9 patients & $\begin{array}{l}\text { Intravenous contrast } \\
\text { agent Fluorescein } \\
\text { enabled distinguishing } \\
\text { normal from abnormal } \\
\text { tissue. } \\
\text { Intravenous contrast } \\
\text { agent 5-aminolevulinic } \\
\text { acid did not produce } \\
\text { diagnosable images. }\end{array}$ \\
\hline 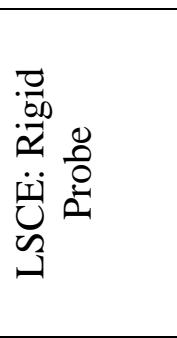 & $\begin{array}{l}\text { Breuskin D } \\
\text { et al., } 2013\end{array}$ & $\begin{array}{l}\text { Confocal laser } \\
\text { endomicroscopy in } \\
\text { neurosurgery: a new } \\
\text { technique with much } \\
\text { potential }\end{array}$ & $\begin{array}{l}\text { Animal } \\
\text { (normal } \\
\text { pig } \\
\text { brain), } \\
\text { cultured } \\
\text { cells \& } \\
\text { ex-vivo }\end{array}$ & 50 specimens & $\begin{array}{l}\text { Histologic features } \\
\text { were demonstrable } \\
\text { using the technique in } \\
\text { some brain primary } \\
\text { tumors }\end{array}$ \\
\hline \multirow{3}{*}{ 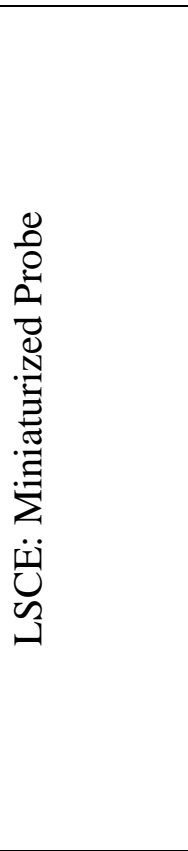 } & $\begin{array}{l}\text { Foersch S et } \\
\text { al., } 2012\end{array}$ & $\begin{array}{l}\text { Confocal laser } \\
\text { endomicroscopy for } \\
\text { diagnosis and } \\
\text { histomorphologic imaging } \\
\text { of brain tumors in vivo }\end{array}$ & $\begin{array}{l}\text { Animal } \\
\text { (Rat) \& } \\
\text { ex-vivo }\end{array}$ & $\begin{array}{l}11-\text { rats } \\
15 \text { ex-vivo } \\
\text { specimens }\end{array}$ & $\begin{array}{l}\text { Overall ability to } \\
\text { provide a diagnosis in } \\
90.85 \% \text { of cases }\end{array}$ \\
\hline & $\begin{array}{l}\text { Peyre M et } \\
\text { al., } 2013\end{array}$ & $\begin{array}{l}\text { Miniaturized handheld } \\
\text { confocal microscopy } \\
\text { identifies focal brain } \\
\text { invasion in a mouse model } \\
\text { of aggressive meningioma }\end{array}$ & $\begin{array}{l}\text { Animal } \\
\text { (mice) \& } \\
\text { ex-vivo }\end{array}$ & 20 mice & $\begin{array}{l}\text { Ability of method in } \\
\text { identifying cytologic } \\
\text { and architectural } \\
\text { criteria of aggressive } \\
\text { meningiomas including } \\
\text { foci of infiltration }\end{array}$ \\
\hline & $\begin{array}{l}\text { Martirosyan } \\
\text { NL et al., } \\
2016\end{array}$ & $\begin{array}{l}\text { Prospective evaluation of } \\
\text { the utility of intraoperative } \\
\text { confocal laser } \\
\text { endomicroscopy in patients } \\
\text { with brain neoplasms using } \\
\text { fluorescein sodium: } \\
\text { experience with } 74 \text { cases }\end{array}$ & $\begin{array}{l}\text { In-vivo } \\
\text { and ex- } \\
\text { vivo }\end{array}$ & 74 patients & $\begin{array}{l}\text { Specificity: } \\
\text { 94\% gliomas } \\
\text { 93\% meningiomas } \\
\text { Sensitivity: } \\
\text { gliomas; } 91 \% \\
\text { meningiomas; } 97 \%\end{array}$ \\
\hline$u \propto \geq$ & Georges $\mathbf{J}$ et & Label-free microscopic & Animal & 5 rats & Proof of Concept in the \\
\hline
\end{tabular}




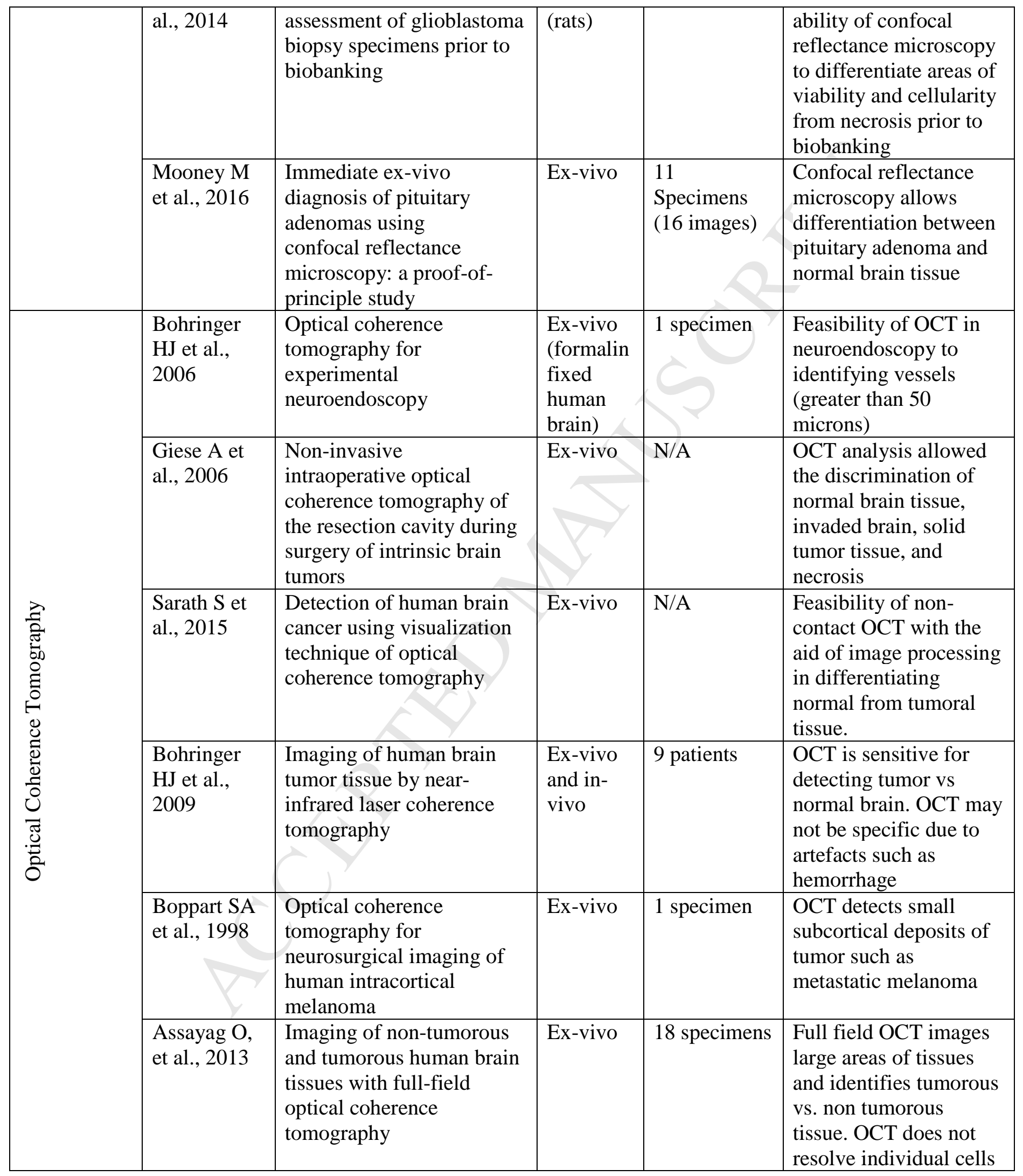




\begin{tabular}{|c|c|c|c|c|c|}
\hline & $\begin{array}{l}\text { Finke M, et } \\
\text { al., } 2012\end{array}$ & $\begin{array}{l}\text { Automatic scanning of } \\
\text { large tissue areas in } \\
\text { neurosurgery using optical } \\
\text { coherence tomography }\end{array}$ & Ex-vivo & 6 specimens & $\begin{array}{l}\text { Ability of performing } \\
\text { automatic OCT scans } \\
\text { of large areas of tissue } \\
\text { to identify foci of tumor }\end{array}$ \\
\hline \multirow{3}{*}{ 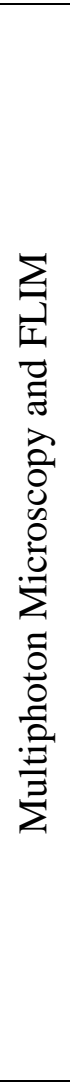 } & $\begin{array}{l}\text { Leppert J et } \\
\text { al., } 2006\end{array}$ & $\begin{array}{l}\text { Multiphoton excitation of } \\
\text { autofluorescence for } \\
\text { microscopy of glioma } \\
\text { tissue }\end{array}$ & $\begin{array}{l}\text { Cultured } \\
\text { cells, } \\
\text { animal }\end{array}$ & N/A & $\begin{array}{l}\text { Demonstrated high } \\
\text { resolution images using } \\
\text { endogenous } \\
\text { fluorophores, and } \\
\text { ability of imaging } \\
\text { single malignant cells }\end{array}$ \\
\hline & $\begin{array}{l}\text { Kantelhardt } \\
\text { S et al., } \\
2007\end{array}$ & $\begin{array}{l}\text { Imaging of brain and brain } \\
\text { tumor specimens by time- } \\
\text { resolved multiphoton } \\
\text { excitation microscopy ex } \\
\text { vivo }\end{array}$ & $\begin{array}{l}\text { Animal, } \\
\text { ex-vivo }\end{array}$ & N/A & $\begin{array}{l}\text { Ability of fluorescence } \\
\text { lifetime in } \\
\text { distinguishing normal } \\
\text { brain tissue from tumor } \\
\text { tissue which } \\
\text { consistently have } \\
\text { longer fluorescent } \\
\text { lifetimes }\end{array}$ \\
\hline & $\begin{array}{l}\text { Kantelhardt } \\
\text { S et al., } \\
2008\end{array}$ & $\begin{array}{l}\text { Multiphoton excitation } \\
\text { fluorescence microscopy of } \\
5 \text {-aminolevulinic acid } \\
\text { induced fluorescence in } \\
\text { experimental gliomas }\end{array}$ & $\begin{array}{l}\text { Cultured } \\
\text { cells, } \\
\text { animal }\end{array}$ & N/A & $\begin{array}{l}\text { fluorescence lifetime } \\
\text { profiles after the } \\
\text { addition of fluorescent } \\
\text { agent 5-ALA allow } \\
\text { differentiation between } \\
\text { tumor and normal brain } \\
\text { more consistently than } \\
\text { endogenous } \\
\text { fluorophores }\end{array}$ \\
\hline \multirow{3}{*}{ 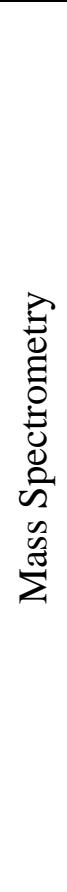 } & $\begin{array}{l}\text { Santagata S } \\
\text { et al., } 2014\end{array}$ & $\begin{array}{l}\text { Intraoperative mass } \\
\text { spectrometry mapping of } \\
\text { an onco-metabolite to } \\
\text { guide brain tumor surgery }\end{array}$ & Ex-vivo & $\begin{array}{l}\text { N/A (at least } \\
35 \text { ) }\end{array}$ & $\begin{array}{l}\text { Ability of mass } \\
\text { spectrometry in } \\
\text { identifying tumor } \\
\text { including IDH-1 } \\
\text { mutations in real time } \\
\text { from freshly biopsied } \\
\text { tissues }\end{array}$ \\
\hline & $\begin{array}{l}\text { Agar NY et } \\
\text { al., } 2011\end{array}$ & $\begin{array}{l}\text { Development of } \\
\text { stereotactic mass } \\
\text { spectrometry for brain } \\
\text { tumor surgery }\end{array}$ & Ex-vivo & 22 specimens & $\begin{array}{l}\text { Ability of mass } \\
\text { spectrometry in } \\
\text { detecting tumor in } \\
\text { tissue ex-vivo with } 3 \\
\text { dimensional mapping } \\
\text { of biopsied sites }\end{array}$ \\
\hline & $\begin{array}{l}\text { Elkhaled A } \\
\text { et al., } 2014\end{array}$ & $\begin{array}{l}\text { Characterization of } \\
\text { metabolites in infiltrating } \\
\text { gliomas using ex vivo }\end{array}$ & Ex-vivo & $\begin{array}{l}126 \\
\text { specimens }\end{array}$ & $\begin{array}{l}\text { Defining characteristic } \\
\text { metabolic profiles in } \\
\text { primary, recurrent and } \\
\text { transformed gliomas } \\
\text { and ability of profiles in } \\
\text { predicting }\end{array}$ \\
\hline
\end{tabular}




\begin{tabular}{|c|c|c|c|c|c|}
\hline & & & & & $\begin{array}{l}\text { transformation of low } \\
\text { grade gliomas. }\end{array}$ \\
\hline & $\begin{array}{l}\text { Schafer KC } \\
\text { et al., } 2011\end{array}$ & $\begin{array}{l}\text { Real time analysis of brain } \\
\text { tissue by direct } \\
\text { combination of ultrasonic } \\
\text { surgical aspiration and } \\
\text { sonic spray mass } \\
\text { spectrometry }\end{array}$ & Ex-vivo & N/A & $\begin{array}{l}\text { Demonstrated ability of } \\
\text { diagnosing tumors } \\
\text { using direct and } \\
\text { immediate mass } \\
\text { spectrometry analysis } \\
\text { of ultrasonically } \\
\text { liquefied tissues. }\end{array}$ \\
\hline \multirow{3}{*}{ 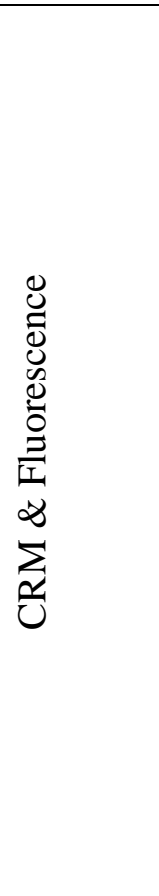 } & $\begin{array}{l}\text { Forest F et } \\
\text { al., } 2015\end{array}$ & $\begin{array}{l}\text { Ex vivo confocal } \\
\text { microscopy imaging to } \\
\text { identify tumor tissue on } \\
\text { freshly removed brain } \\
\text { sample }\end{array}$ & Ex-vivo & 19 specimens & $\begin{array}{l}\text { Ability of combined } \\
\text { reflectance and } \\
\text { fluorescence confocal } \\
\text { microscopy in } \\
\text { identifying brain } \\
\text { tumors }\end{array}$ \\
\hline & $\begin{array}{l}\text { Wirth D et } \\
\text { al., } 2012\end{array}$ & $\begin{array}{l}\text { Identifying brain } \\
\text { neoplasms using dye- } \\
\text { enhanced multimodal } \\
\text { confocal imaging }\end{array}$ & Ex-vivo & $\begin{array}{l}119 \\
\text { specimens }\end{array}$ & $\begin{array}{l}\text { Ability of combined } \\
\text { reflectance and } \\
\text { fluorescence confocal } \\
\text { microscopy in } \\
\text { identifying brain } \\
\text { tumors with good } \\
\text { correlation with H\&E } \\
\text { histology. }\end{array}$ \\
\hline & $\begin{array}{l}\text { Snuderl M } \\
\text { et al., } 2013\end{array}$ & $\begin{array}{l}\text { Dye-enhanced multimodal } \\
\text { confocal imaging as a } \\
\text { novel approach to } \\
\text { intraoperative diagnosis of } \\
\text { brain tumors }\end{array}$ & Ex-vivo & 37 specimens & $\begin{array}{l}\text { High sensitivity and } \\
\text { specificity ( } 95 \% \text { and } \\
100 \% \text { respectively) for } \\
\text { detecting normal vs. } \\
\text { abnormal brain tissue. }\end{array}$ \\
\hline 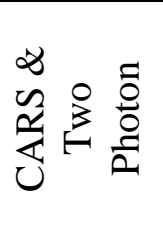 & $\begin{array}{l}\text { Romeike BF } \\
\text { et al., } 2015\end{array}$ & $\begin{array}{l}\text { Coherent anti-Stokes } \\
\text { Raman scattering and two } \\
\text { photon excited } \\
\text { fluorescence for } \\
\text { neurosurgery }\end{array}$ & Ex-vivo & 55 specimens & $\begin{array}{l}\text { Demonstrated great } \\
\text { ability to provide } \\
\text { diagnoses without } \\
\text { addition of contrast } \\
\text { material }\end{array}$ \\
\hline
\end{tabular}

Abbreviations: CARS: Coherent antistokes raman spectroscopy; CRM: Confocal Refelectance Microscopy; FLIM: Fluorescence lifetime microscopy; LSCE: Laser scanning confocal endomicroscopy; OCT: Optical coherence tomography 


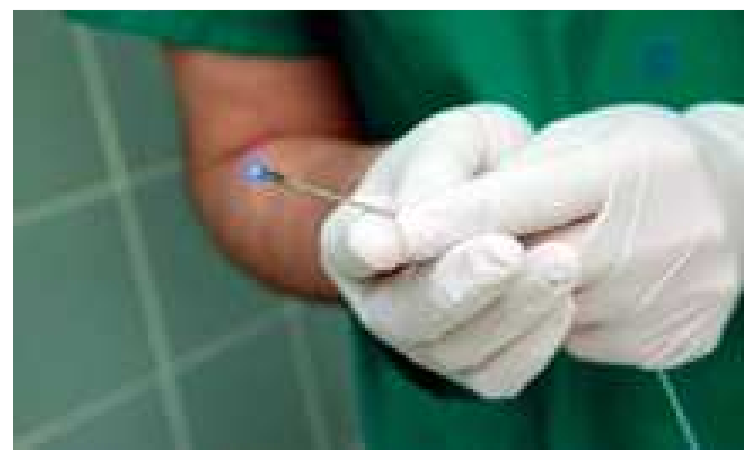




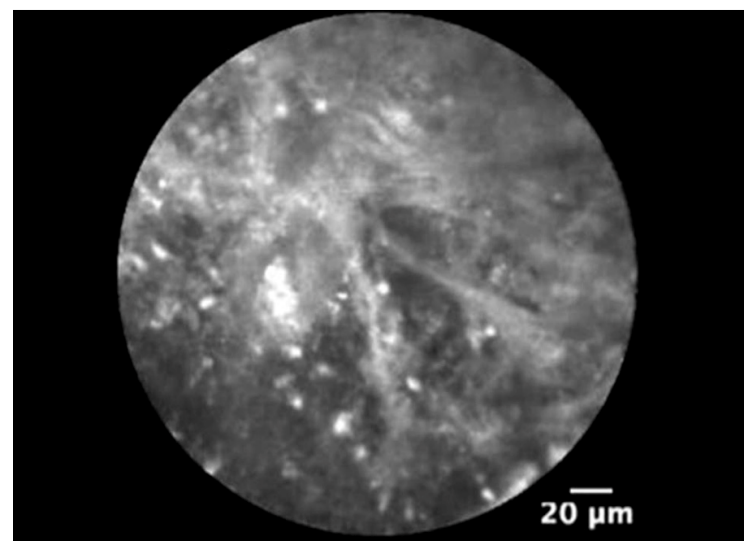




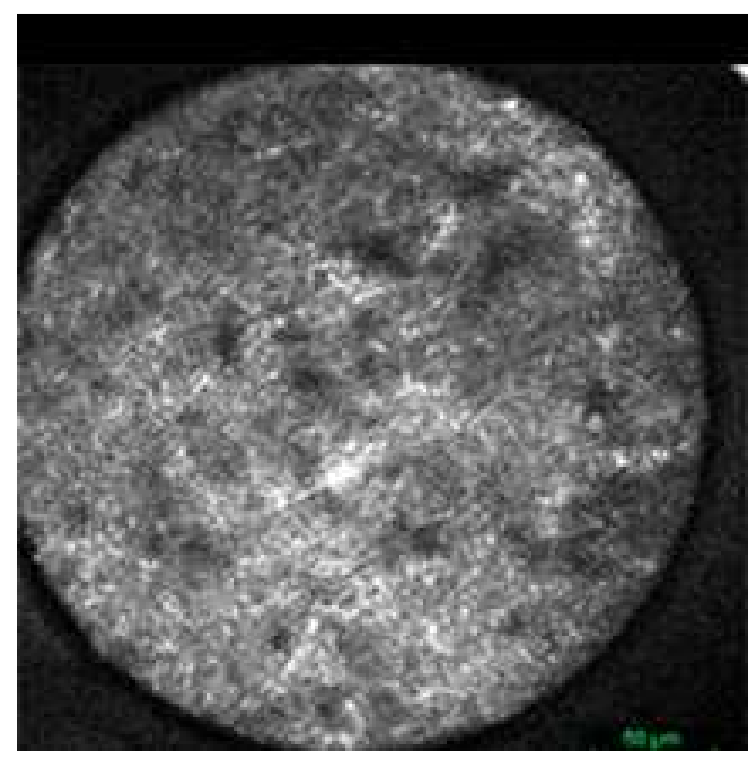




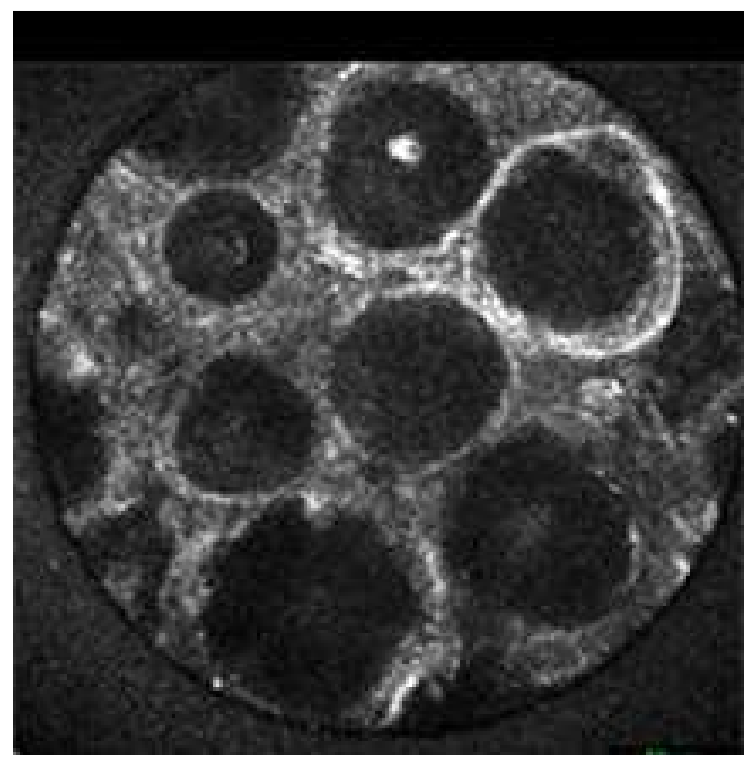




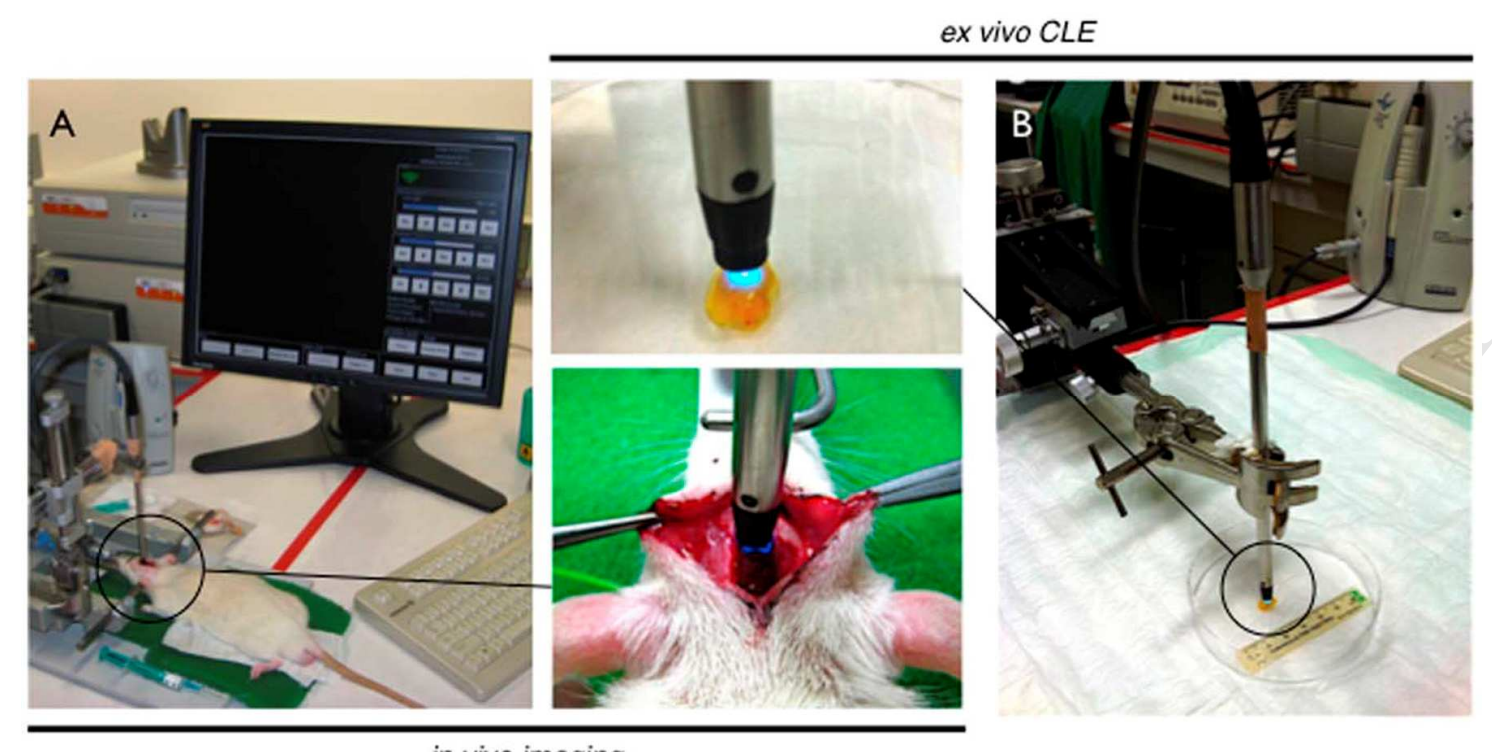

in vivo imaging 

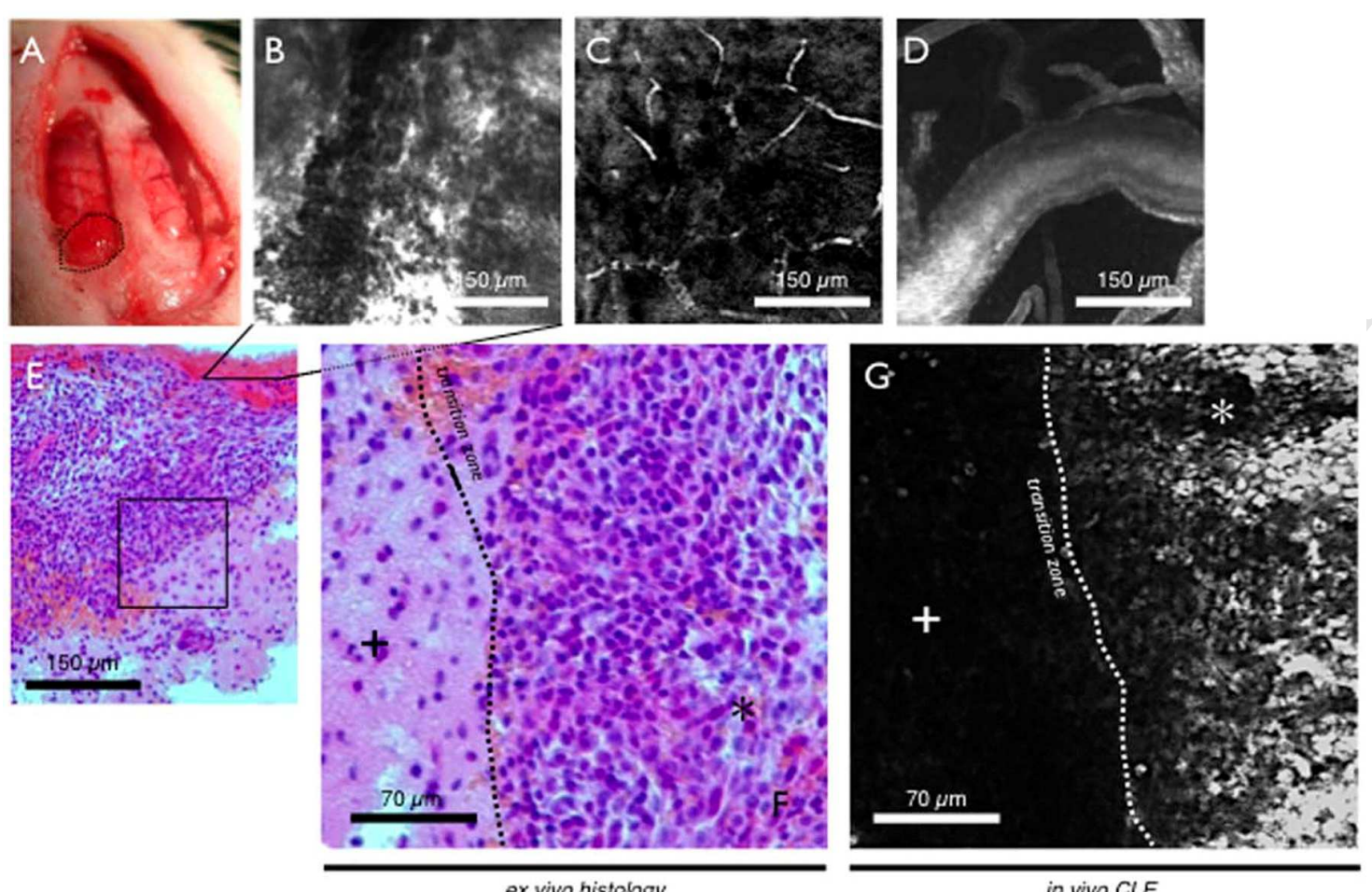

ex vivo histology

in vivo $C L E$ 
A
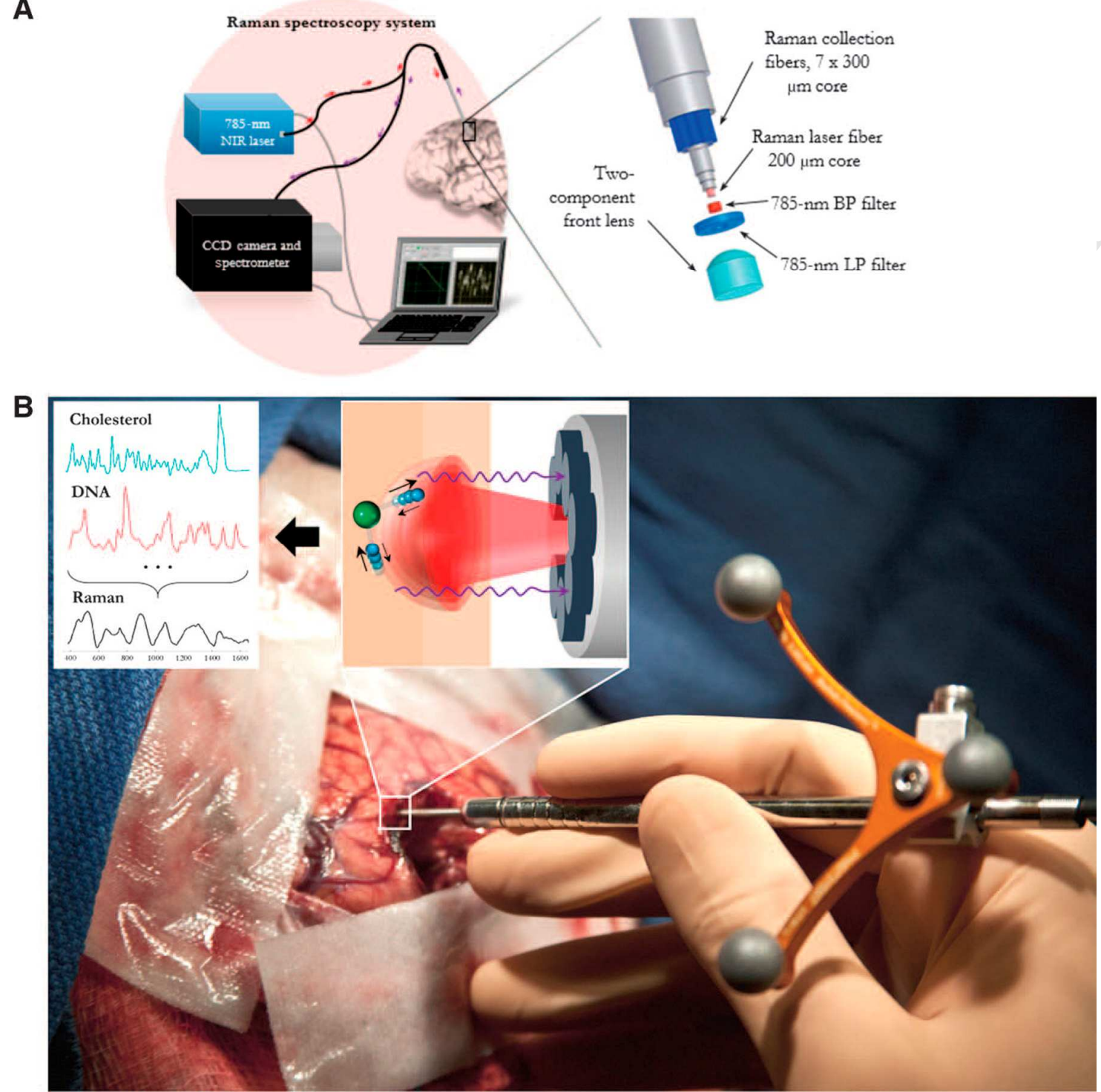

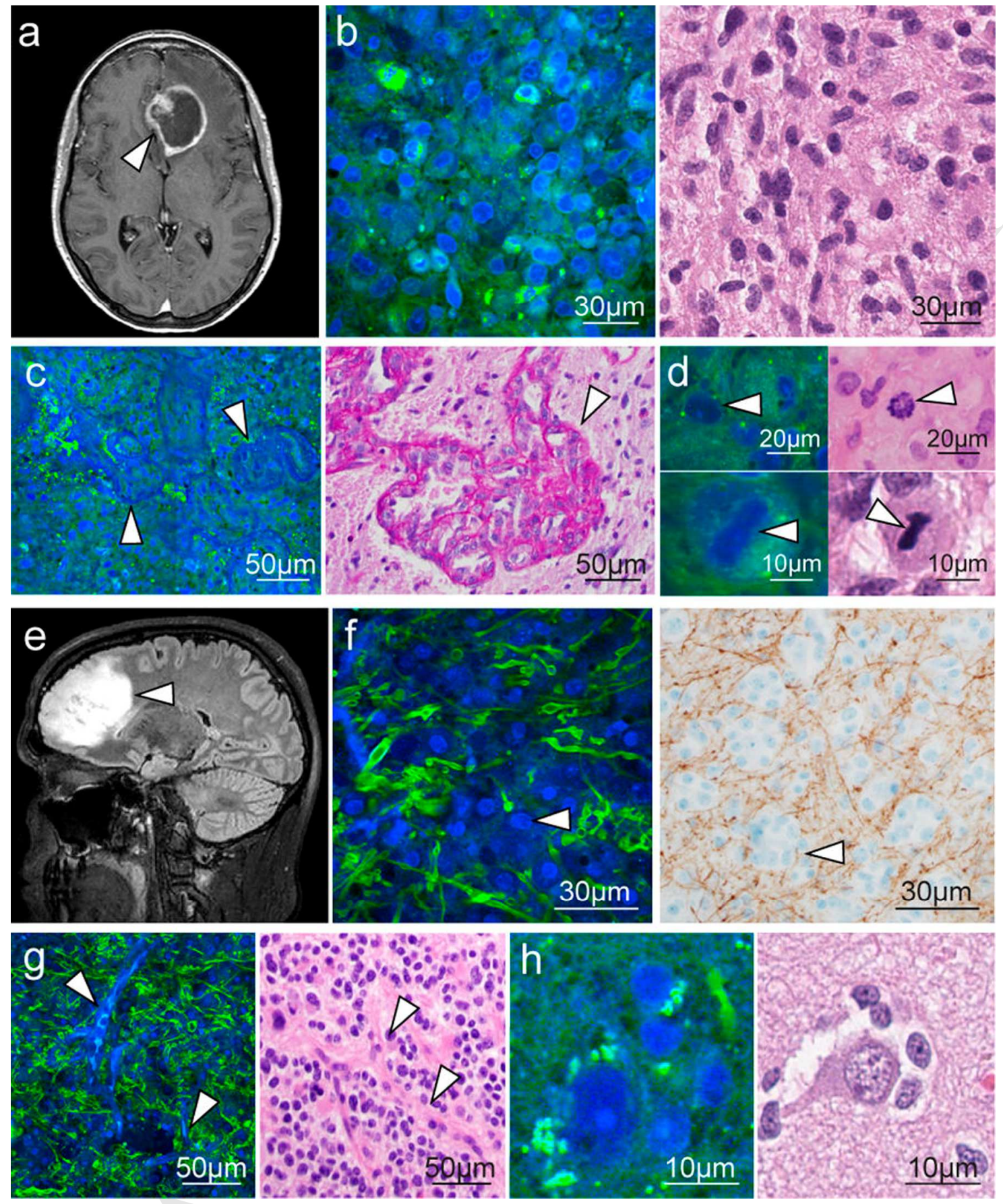


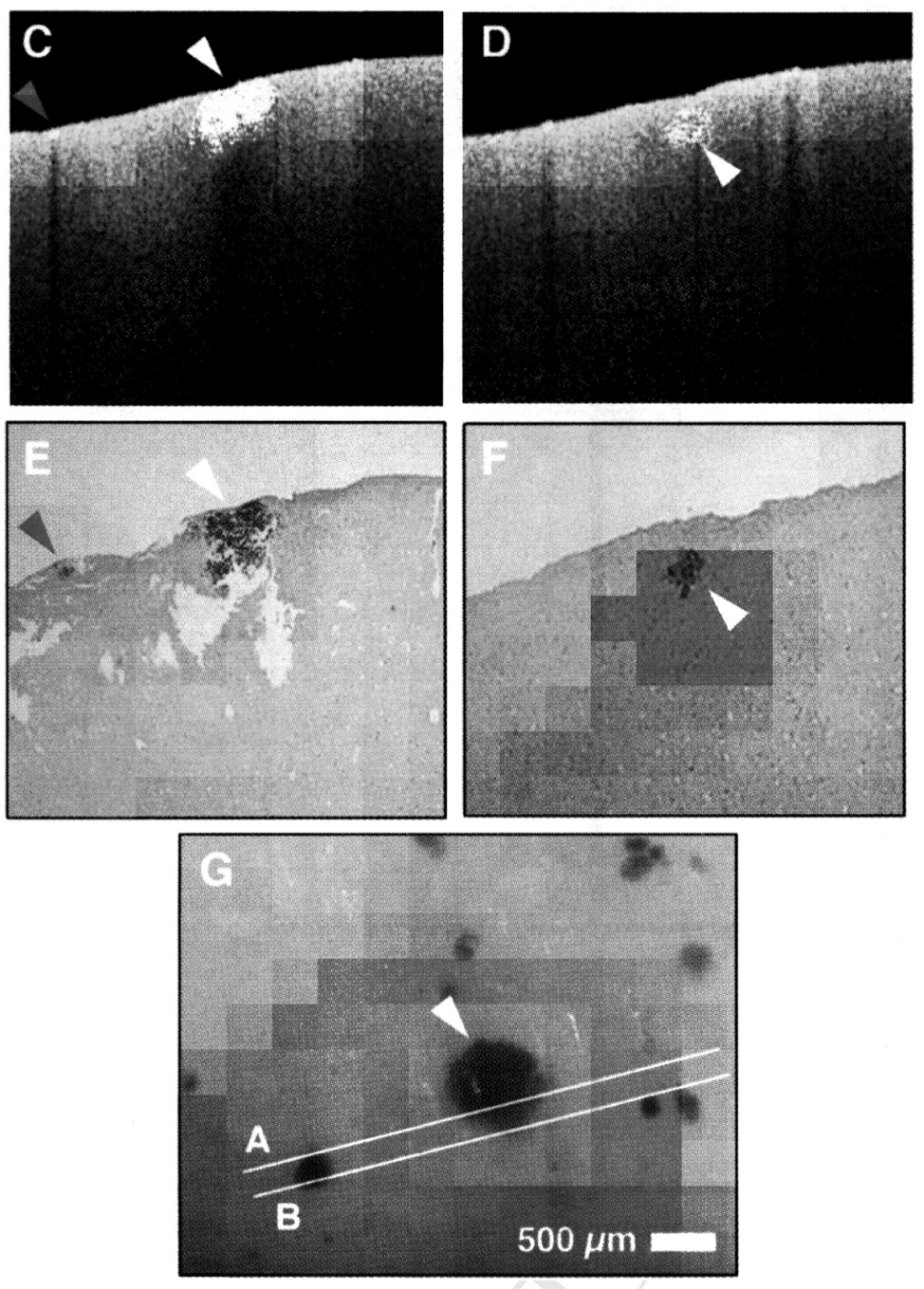



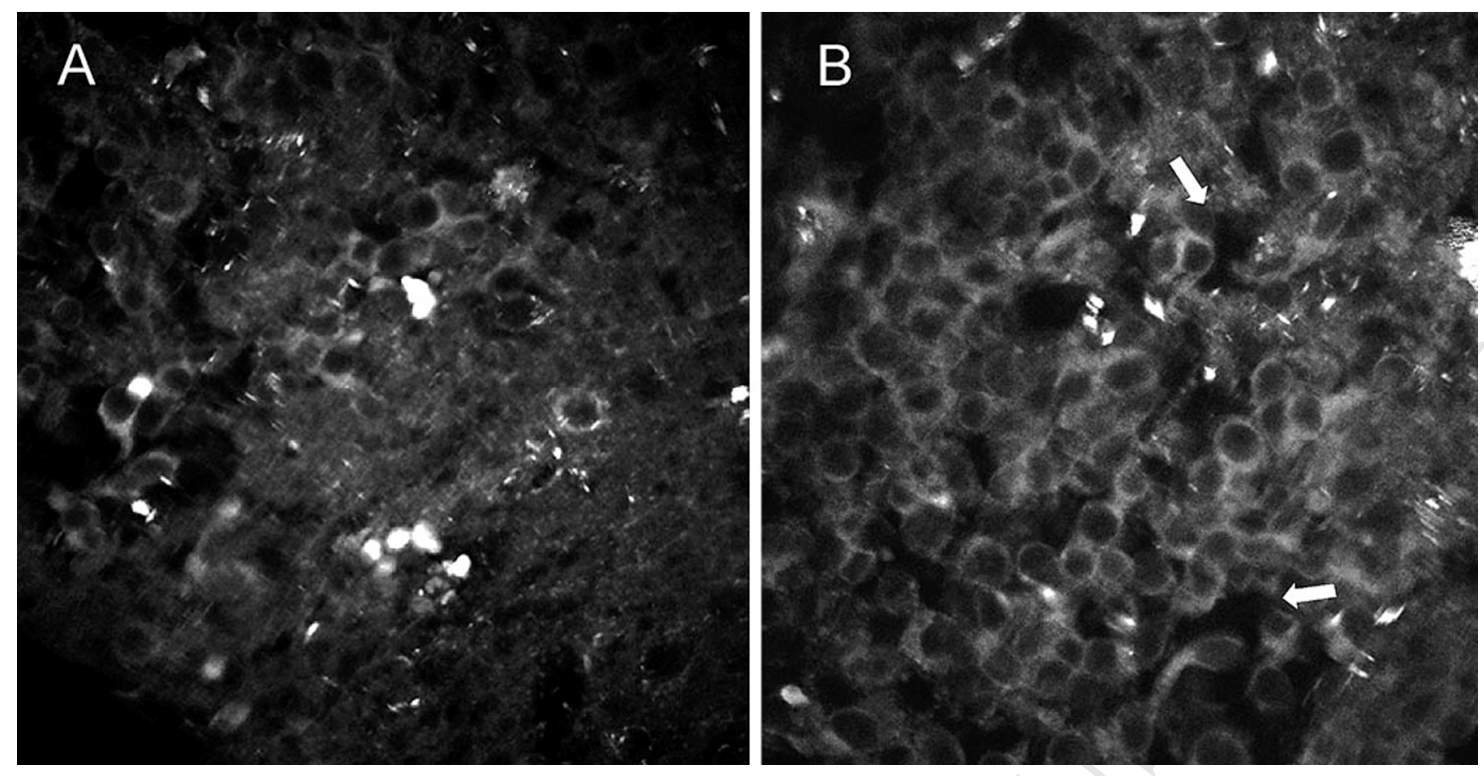


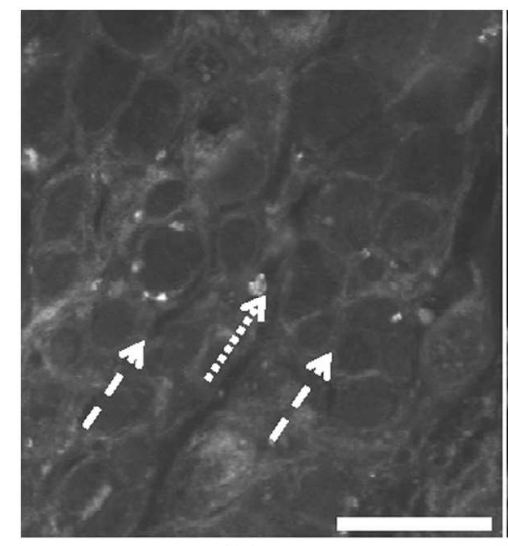

(a)

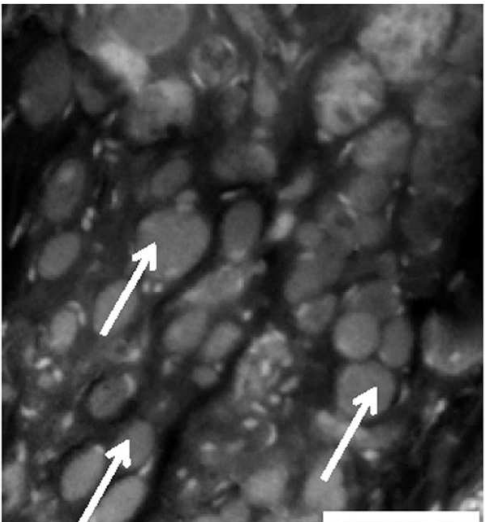

(b)

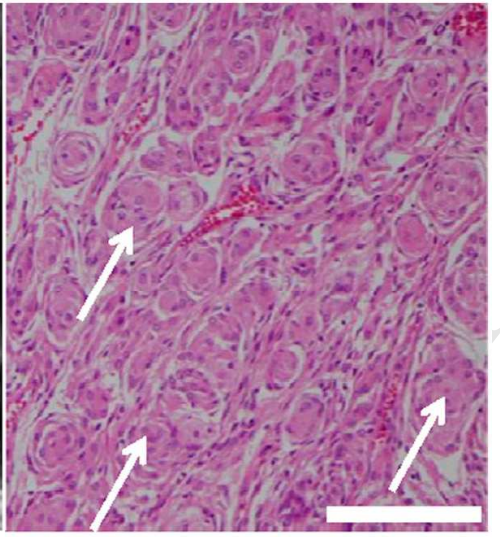

(c) 


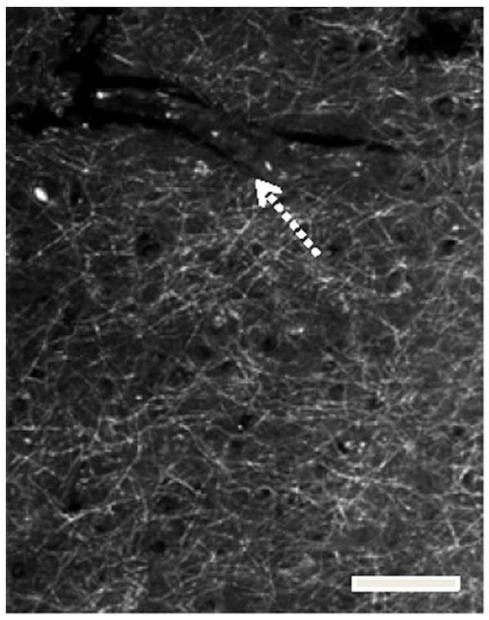

(a)

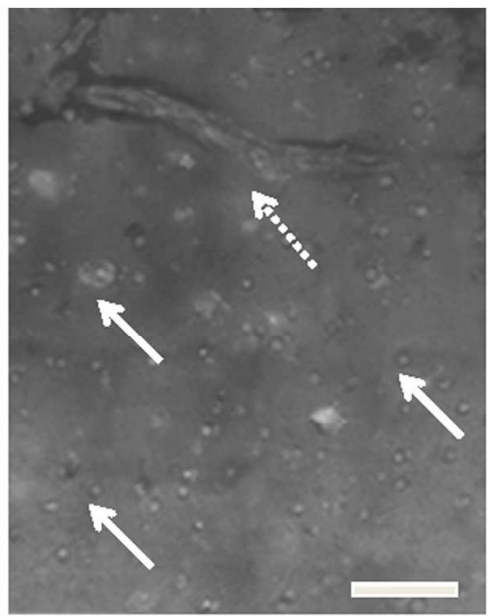

(b)

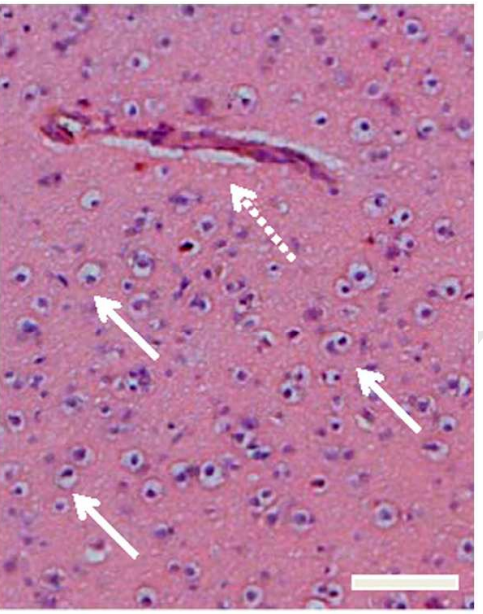

(c) 

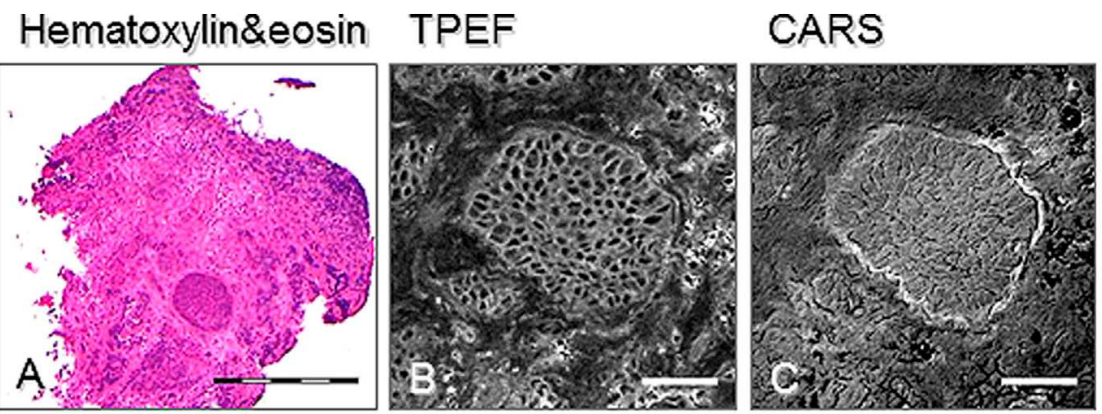

CARS\&TPEF
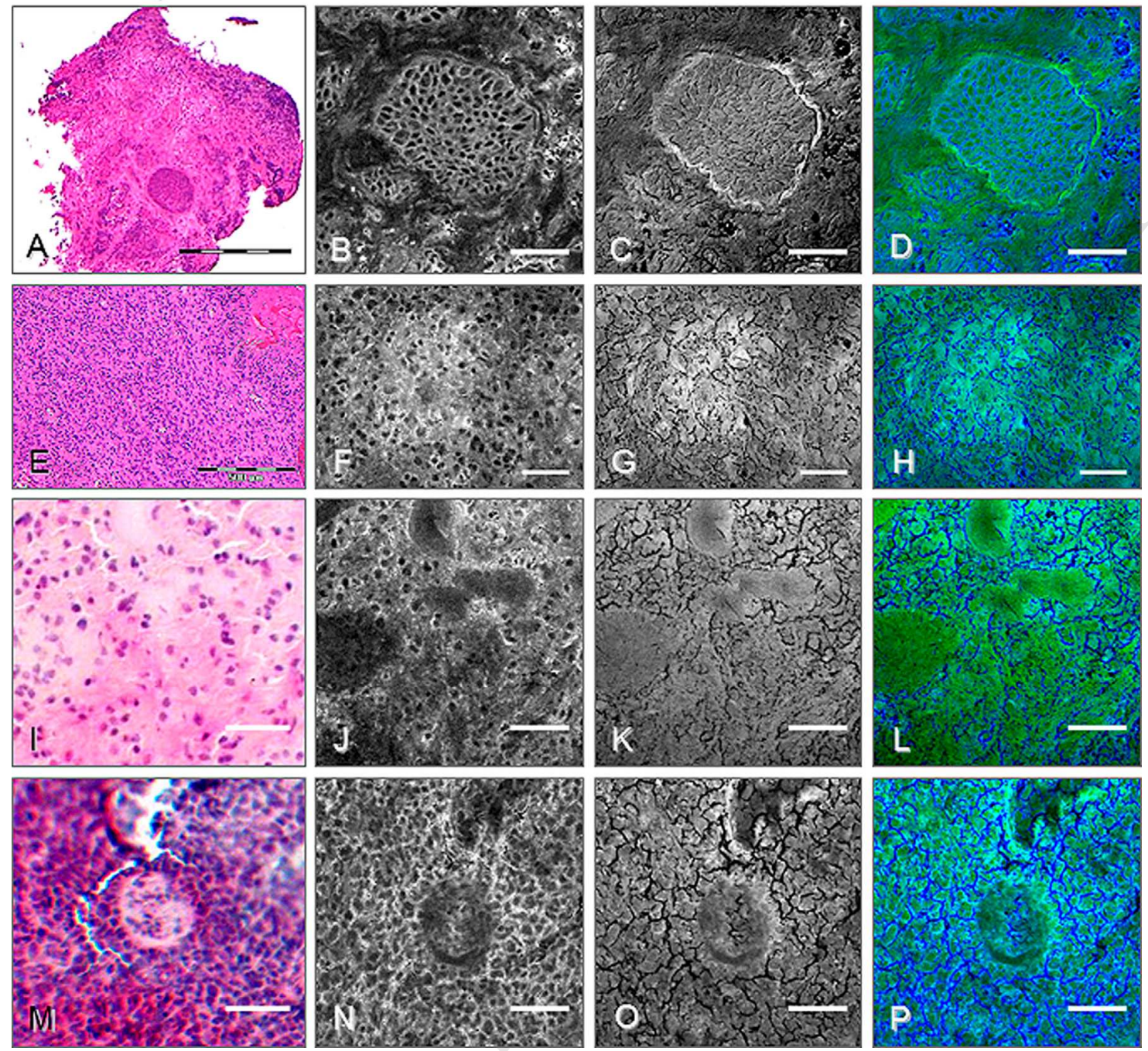


\section{Highlights}

- Multiple imaging technologies for microscopy are outlined and evaluated

- Advantages and disadvantages of pertinent microscopy methods are discussed

- Current microscopic neurosurgical imaging requires refinement or in-vivo testing

- Combination of different imaging methods provides best in-vivo imaging 


\section{Abbreviations \\ In Vivo Microscopy in Neurosurgical Oncology}

Review Article

2-HG: 2-hydroxyglutarate

5ALA: 5-aminolevulinic acid

BLZ-100: tumor paint

CARS: coherent anti-stokes Raman scattering

CRM: confocal reflectance microscopy

CRS: coherent Raman spectroscopy

LSCE: laser scanning confocal endomicroscopy

FNa: fluorescein sodium

FLIM: fluorescence lifetime microscopy

ICG: indocyanine green

OCT: optical coherence tomography

SRS: stimulated Raman scattering 